\title{
A model-based exploration of farm-household livelihood and nutrition indicators to guide nutrition-sensitive agriculture interventions
}

\author{
Natalia Estrada-Carmona ${ }^{1,2}$ (D) Jessica E. Raneri ${ }^{2,3} \cdot$ Stephanie Alvarez ${ }^{1}$. Carl Timler ${ }^{1} \cdot$ Shantonu Abe Chatterjee ${ }^{1} \cdot$ \\ Lenora Ditzler ${ }^{1}$ • Gina Kennedy ${ }^{2}$ - Roseline Remans ${ }^{2}$ • Inge Brouwer ${ }^{4}$. Karin Borgonjen-van den Berg ${ }^{4}$. \\ Elise F. Talsma ${ }^{4}$ • Jeroen C. J. Groot ${ }^{1,5,6}$
}

Received: 14 September 2018 / Accepted: 16 October 2019 / Published online: 4 December 2019

(C) The Author(s) 2019

\begin{abstract}
Assessing progress towards healthier people, farms and landscapes through nutrition-sensitive agriculture (NSA) requires transdisciplinary methods with robust models and metrics. Farm-household models could facilitate disentangling the complex agriculture-nutrition nexus, by jointly assessing performance indicators on different farm system components such as farm productivity, farm environmental performance, household nutrition, and livelihoods. We, therefore, applied a farm-household model, FarmDESIGN, expanded to more comprehensively capture household nutrition and production diversity, diet diversity, and nutrient adequacy metrics. We estimated the potential contribution of an NSA intervention targeting the diversification of home gardens, aimed at reducing nutritional gaps and improving livelihoods in rural Vietnam. We addressed three central questions: (1) Do 'Selected Crops' (i.e. crops identified in a participatory process) in the intervention contribute to satisfying household dietary requirements?; (2) Does the adoption of Selected Crops contribute to improving household livelihoods (i.e. does it increase leisure time for non-earning activities as well as the dispensable budget)?; and (3) Do the proposed nutritionrelated metrics estimate the contribution of home-garden diversification towards satisfying household dietary requirements? Results indicate trade-offs between nutrition and dispensable budget, with limited farm-household configurations leading to jointly improved nutrition and livelihoods. FarmDESIGN facilitated testing the robustness and limitations of commonly used metrics to monitor progress towards NSA. Results indicate that most of the production diversity metrics performed poorly at predicting desirable nutritional outcomes in this modelling study. This study demonstrates that farm-household models can facilitate anticipating the effect (positive or negative) of agricultural interventions on nutrition and the environment, identifying complementary interventions for significant and positive results and helping to foresee the trade-offs that farm-households could face. Furthermore, FarmDESIGN could contribute to identifying agreed-upon and robust metrics for measuring nutritional outcomes at the farm-household level, to allow comparability between contexts and NSA interventions.
\end{abstract}

Keywords Home garden · Multi-objective optimisation · Crop diversification $\cdot$ Farm-household model $\cdot$ Human nutrition metrics

Electronic supplementary material The online version of this article (https://doi.org/10.1007/s12571-019-00985-0) contains supplementary material, which is available to authorized users.

Natalia Estrada-Carmona

n.e.carmona@ cgiar.org

1 Farming Systems Ecology Group, Wageningen University and Research, 6700AK, Wageningen, The Netherlands

2 Bioversity International, Parc Scientifique Agropolis II, 1990 Boulevard de la Lironde, 34397 Montpellier, France

3 Department of Food Safety and Food Quality, Faculty of Bioscience Engineering, Ghent University, 9000 Ghent, Belgium
4 Division of Human Nutrition and Health, Wageningen University and Research, 67000AA, Wageningen, The Netherlands

5 Bioversity International, Viale dei Tre Denari, 472/a, 00054 Maccarese, Fiumicino, Italy

6 International Maize and Wheat Improvement Center (CIMMYT), Carretera México-Veracruz, Km. 45, El Batán,

56237 Texcoco, Mexico 


\section{Introduction}

Worldwide commitment and interest in supporting nutritionsensitive agriculture (NSA) is growing across multiple sectors (Ruel et al. 2018). Programmes, research and investment policy can be defined as nutrition-sensitive if they incorporate an aim to improve the overall nutritional status by addressing the underlying causes of nutrition (Herforth and Ballard 2016). Addressing the underlying causes include improving access to safe and nutritious food, reducing health risks through responsible agricultural practices that protect natural resources and human health, improving nutrition knowledge and norms, improving income and empowering Women (Herforth and Ballard 2016). The role of agriculture in enhancing nutrition is highly recognized although the evidence of its contribution remains weak and mixed (Herforth and Ballard 2016; Turner et al. 2014; Webb and Kennedy 2014). For example, increasing on-farm production diversity is perceived as an effective approach towards improving smallholders' diet diversity and nutrition. Nonetheless, this perception was contested by Sibhatu and Qaim (2018) after analysing 45 original studies that indicated a positive but small average marginal effect of production diversity on dietary diversity. Ruel et al. (2018), on the other hand, found evidence from 44 carefully designed nutrition-sensitive studies where production diversity was promoted and subsequently led to improved access to nutritious food, which increased the quality of the diet for the most vulnerable (i.e. women and children) (Ruel et al. 2018). The mixed evidence is due to methodological limitations (e.g. sample sizes, time frame), contextual and seasonal constraints, lack of comparability of the agricultural interventions, nonhomogeneity of units of observation (e.g. households, women and children) and variability of metrics (Ruel et al. 2018; Verger et al. 2019; Herforth and Ballard 2016; Turner et al. 2014; Webb and Kennedy 2014).

Assessing the agriculture-nutrition nexus is challenging since it is affected by complex, dynamic and scaledependent interlinkages among farms, markets, wild foods, diets, intra-household and gender dynamics (Bellon et al. 2016; Remans et al. 2015). For example, contextual factors such as competing labour uses (on- farm vs. off- farm), food availability from on- and off-farm sources (e.g. markets), environmental constraints (e.g. poor soils), and socio-economic status and gender dynamics (e.g. income; and equity) all shape household decisions around on-farm production (Ditzler et al. 2018). These factors also shape the performance of the farm, farm-household resources, crop/varietal preferences, and objectives (Ditzler et al. 2019; Groot et al. 2012). Thus, accounting for contextual factors at the farm-household level could aid in identifying constraints in the adoption of NSA interventions and support the achievement of positive nutritional outcomes (Ruel et al. 2018; Herforth and Ballard 2016).
In general, the most commonly listed and documented knowledge gaps that limit the guidance and planning of NSA interventions include: (1) hypothesizing ex-ante NSA intervention impact pathways; (2) anticipating the effect (positive or negative) of the interventions on nutrition and the environment; (3) identifying complementary interventions for significant and positive impacts; and (4) anticipating the trade-offs that a farm-household could face (Ruel et al. 2018; Herforth and Ballard 2016). There is also a lack of emphasis on guaranteeing access to and consumption of high-quality diets by all household members (rather than just one target group, e.g. women or children); a logical and achievable approach for NSA and important for global development (Ruel et al. 2018).

For an integrated analysis, system-based models could play a larger role in guiding and planning NSA interventions. Whole farm-household models, capture the diverse household and production system components and their complex interactions, and so properly reflect the various outcomes linked to production, income, environmental impacts, well-being, gender, health and quality of life (e.g. Jones et al. 2017; Van Ittersum et al. 1998). These models can improve the understanding, and contribute to the analysis of, the 'farm-household' defined as a family-run enterprise, the household managing it and the off-farm income-generating activities by household members (Ditzler et al. 2018, 2019). FarmDESIGN is a farm-household model developed to represent the farm-household and the flow of resources among the farm components (crops, soil, animals, and manure) within and outside the farm (e.g. soil nutrient losses) (Fig. 1) (Groot et al. 2012). We expanded the FarmDESIGN model to calculate various farm-household performance indicators in order to capture more accurately farm-household budget, labour and nutrition (farm-household budget and labour modules explained in detail in Ditzler et al. 2019; Fig. 1 and Table 1). The 'Human nutrition' module integrates various performance indicators that have been proposed to monitor progress towards NSA interventions (e.g. Gustafson et al. 2015; Herforth et al. 2016; Melesse et al. 2019) and to measure different aspects related to nutrition such as food consumption patterns, diet diversity, nutrient supply and nutrient adequacy. For instance, FarmDESIGN facilitates conducting farmhousehold scenario analysis through optimization routines (Ditzler et al. 2019; Groot et al. 2012). Consequently, the model has the potential to contribute valuable information to the design and guide of NSA interventions by jointly quantifying performance indicators across socio-economic, productive, environmental and nutrition farm-household domains.

Our study tested the expanded FarmDESIGN farmhousehold model to provide guidance and planning on NSA interventions, and tested the performance of the incorporated metrics in the 'Human nutrition' module. We used a case study in Vietnam, where diversifying home gardens with 


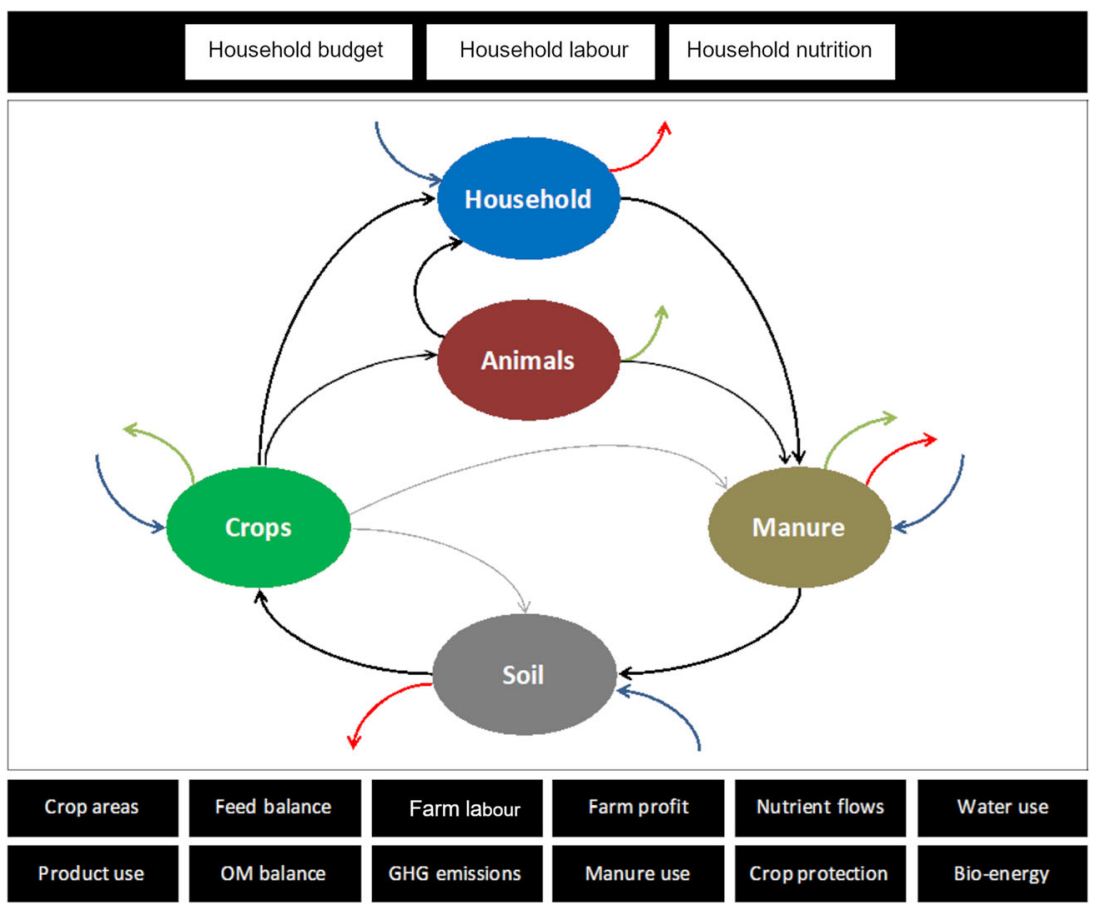

Fig. 1 Schematic representation of the FarmDESIGN model showing farm resource flows (i.e. cash, labour, and food) among the farm components and the household. Blue arrows represent inflows, while other arrows denote product outflows (green) or losses (red). The black and grey arrows indicate resource flows within the farm--household system. Boxes indicate modules that calculate indicators for the farm

nutritious crops selected through a participatory approach was undertaken as an NSA intervention. Our overall aim was to test the impact of a specific nutrition-sensitive intervention, which, in our study's case, is crop diversification targeted to home gardens for improving diets and livelihoods. Hence, we addressed three central questions: (1) Do 'Selected Crops' (i.e. crops identified in a participatory process) in the intervention contribute to satisfying household dietary requirements?; (2) Does the adoption of Selected Crops contribute to improving household livelihoods (i.e. does it increase leisure time for non-earning activities as well as the dispensable budget)?; and (3) Do the proposed nutrition-related metrics estimate the contribution of home-garden diversification towards satisfying household dietary requirements?

\section{Materials and methods}

\subsection{The expanded FarmDESIGN model}

The previous version of the FarmDESIGN model was unable to capture off-farm data for the household's employment, leisure activities and food use (Ditzler et al. 2019). The model therefore could not capture the different livelihood strategies or the food availability of the farm-household. We overcame this limitation by adding the household and its members to the enterprise (black boxes at the bottom) and the household (white boxes at the top). The three new modules related to the household calculate diverse performance indicators at the farm-household level (see Table 1). $\mathrm{OM}=$ organic matter; $\mathrm{GHG}=$ greenhouse gases; Product use $=$ allocation of crop and animal products produced on- farm or sourced off farm. Source: From Ditzler et al. (2019)

model as entities and placing the family enterprise (i.e. the farm) within the farm-household. This change facilitated calculating diverse farm-household performance indicators for the productive, socio-economic, environmental, and nutritional domains. Therefore, the addition of three new farmhousehold modules 'Household budget,' 'Household labour' and 'Household nutrition' widens the applicability of FarmDESIGN for modelling farming systems (Ditzler et al. 2019). Ditzler et al. (2019) detailed the changes in the 'Household budget,' and 'Household labour' modules in particular (Fig. 1).

Overall, the model represents the farm-household on an annual basis and integrates a Pareto-based multi-objective optimization algorithm with a bio-economical model to generate alternative farm configurations (Groot et al. 2016; 2012). The alternative farm configurations are feasible farm-household configurations that deviate from the initially represented farm-household. The alternative farm configurations allocate available resources depending on the objectives optimized for, the decision variables and the constraints (see Table 1 for a detailed description of the selected objectives, decision variables, and constraints). The objectives in the optimization can be any indicator assessing farm-household performance across domains (Groot et al. 2012; Ditzler et al. 2019). Decision variables determine the manoeuvring space and indicate which aspects of the farm-household configuration, 


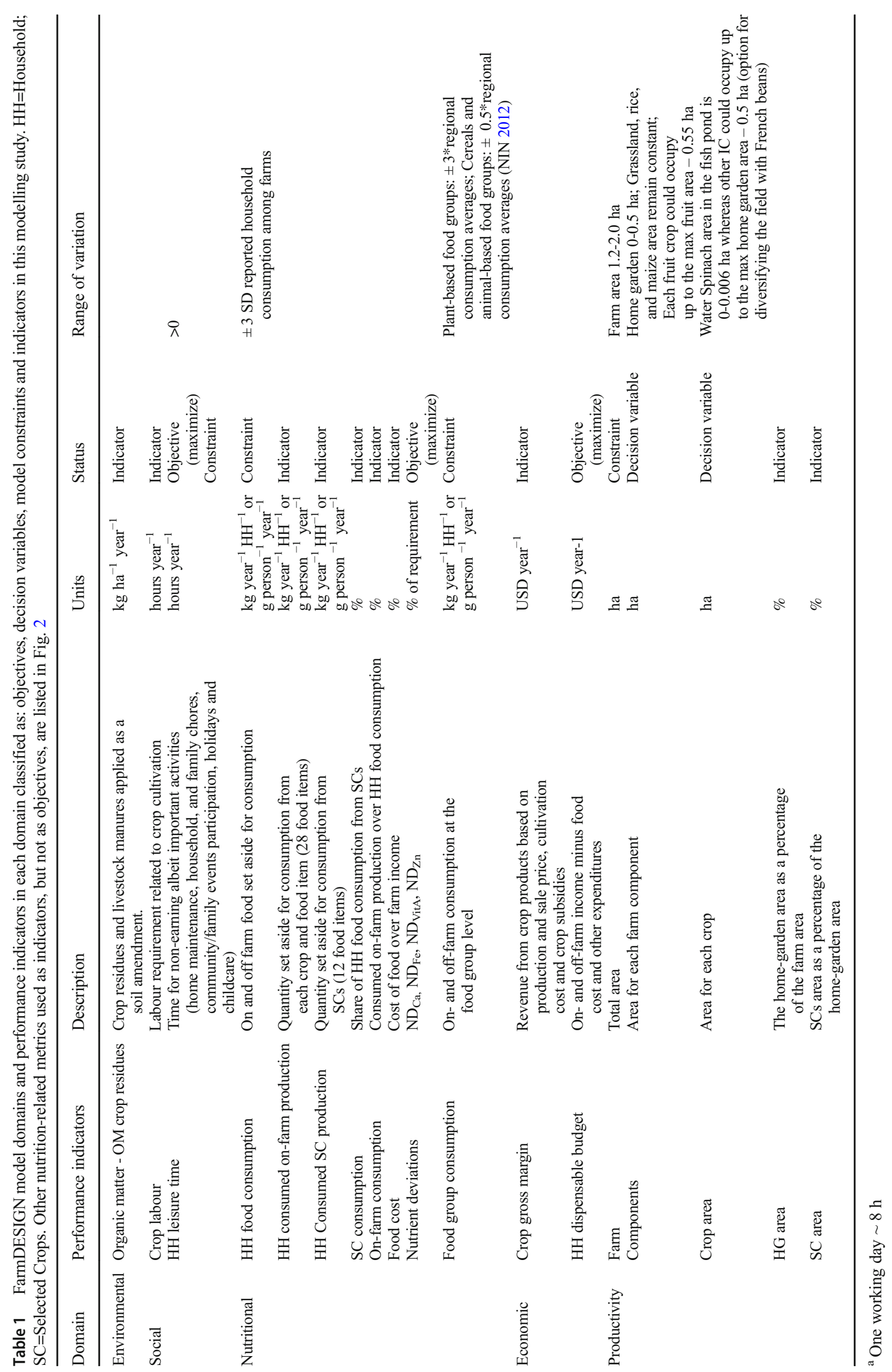


resource allocation and input levels can vary in the optimization (Groot et al. 2012,); whereas constraints limit the exploration space so that the model yields realistic and desirable farm configurations (Groot et al. 2012). Therefore, alternative farm configurations are useful for exploring trade-offs and synergies when optimizing farm-household objectives across selected domains.

\subsection{The 'human nutrition' module in FarmDESIGN}

The new 'Human nutrition' module assesses the potential contribution of a household's on-farm annual production (i.e. plants, livestock and fish) or off-farm food acquisition (e.g. purchased from the market) to meet the dietary requirements of the household. The new module calculates several metrics that capture production diversity, diet diversity and nutrient adequacy (see Fig. 2, Appendix 1 for detailed metrics description, equations, assumptions, input data and limitations).

The 'Human nutrition' module calculates diet diversity metrics from household diet assessments, whereas production diversity is calculated using farming systems characterization $\left(\right.$ Diet $-{ }^{\mathrm{D}}$; Production $-{ }^{\mathrm{P}}$ ). Nutrient adequacy metrics assess the sufficiency of nutrient intake from a given diet and consumption pattern. The nutrient adequacy metric in FarmDESIGN considers dietary requirements of all household members by using dietary reference intakes, either as recommended dietary allowances or as estimated average requirements depending on data availability; whereas food composition tables are used to estimate the nutrient intakes (see Table 2). The new module also accounts for food consumption patterns, or food patterns at the food group level, and nutrient loss due to processing and cooking procedures through nutrient retention factors.

Diet diversity, production diversity and nutrient adequacy metrics are divided into two groups of count-based and abundance-based metrics (Fig. 2). Count-based metrics are estimated using the presence of unique food items or species. For example, the species richness of a diet is measured as the number of species consumed in the diet from on- and off- farm sources ( $\mathrm{SR}^{\mathrm{D}}$; e.g. Lachat et al. 2017), whereas the species richness in the production system is measured as the number of harvested crops for consumption $\left(\mathrm{SR}^{\mathrm{P}}\right.$; e.g. Herrero et al. 2017) (Fig. 2, Appendix 1). The household dietary diversity score (HDDS) measures the number of food groups in the diet by any household member in the past $24 \mathrm{~h}$ (includes 12 food groups in the score) and is a proxy indicator mainly for household food security access (Kennedy et al. 2011; Verger et al. 2019). The nutritional functional diversity metric considers both the species diversity and the specific characteristics of each species, in this case the nutrient profiles (Petchey and Gaston 2007). The nutrient profiles for each species or food item (i.e. from food composition tables) were standardized by a reference adult, in this case, the dietary reference intakes for an adult male in the age group of 19-50 years. Then, the nutrient contribution of each food item was used to create a tree diagram (functional dendrogram) where each branch represents one species or food item. Therefore, the nutritional functional diversity metric is the Euclidian distance among food items in the tree diagram, where lower values indicate food items that are closer together and have similar nutrient profiles, whereas larger values suggest dissimilar food items contributing to a wider range of nutrients. The tree diagram was created using 'vegan' and 'hclust' packages in R (Oksanen et al. 2016; R Core Team 2016) and as recommended by Petchey and Gaston (2007). FarmDESIGN uses the tree diagram to calculate the nutritional functional diversity of the $\operatorname{diet}\left(\mathrm{NFD}^{\mathrm{D}}\right)$ and the harvested crops for consumption $\left(\mathrm{NFD}^{\mathrm{P}}\right)$ (see Fig. 2, Appendix 1).

FarmDESIGN also incorporates other commonly used metrics for assessing food items' abundance in diets and

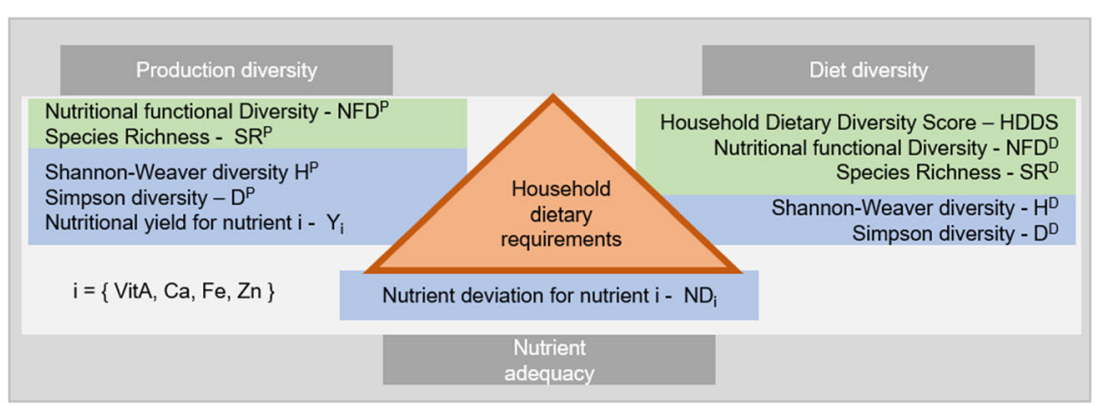

Fig. 2 Metrics included in this modelling study calculated with the new 'Human Nutrition' module within the FarmDESIGN model (see Appendix 1 for a detailed description of each metric). The metrics capture the different components of species diversity (i.e. species richness and abundance) and their nutritional contribution. Green and blue areas indicate count- and abundance-based metrics, respectively. The metrics are calculated for on-farm production set aside for household consumption (superscript $^{\mathrm{P}}$ ) and for the diet (superscript ${ }^{\mathrm{D}}$ ) by accounting for the on- and off-farm food set aside for household consumption. The nutrient adequacy metric is calculated by considering the combined nutritional demand based on the age and gender of each household member. The nutritional functional diversity considers 13 different nutrients (i) whereas the nutrient deviation and nutrient yield metrics focus on the household nutrient requirements and food contributions for likely deficient nutrients such as Vitamin A, Zn, Ca, Fe 
Table 2 Description of the dietary reference intakes

Dietary reference intakes (DRI)

A set of nutrient-based reference values that indicate the average daily nutrient intake that is recommended to ensure the absence of signs of the nutrients' deficiency, as well as a reduction in the risk of chronic degenerative disease

Estimated average requirements (EAR)

EAR is the average daily nutrient intake level estimated to meet the requirement of half the healthy individuals in a particular life stage and gender group
Recommended dietary allowance (RDA):

RDA is the average daily nutrient intake level that is sufficient to meet the nutrient requirement of nearly all (97 to $98 \%$ ) healthy individuals in a particular stage of life and gender group.

Source: IOM (2003) and Devaney and Barr (2002)

production for consumption. The Shannon-Weaver $(\mathrm{H})$ or Simpson (D) diversity indexes jointly assess species richness and distribution evenness. Therefore, both indexes indicate if diets $\left(\mathrm{H}^{\mathrm{D}}, \mathrm{D}^{\mathrm{D}}\right)$ or the food production for consumption $\left(\mathrm{H}^{\mathrm{P}}\right.$, $\mathrm{D}^{\mathrm{P}}$ ) are dominated by one food item or crop species respectively (see Appendix 1 for a detailed description of these metrics). The Shannon-Weaver $(\mathrm{H})$ index is also often calculated to assess the overall diversity of the production areas and not only those set aside for household consumption, for instance we also calculated this index to calculate all the crops planted in the home garden $\left(\mathrm{H}_{\mathrm{HG}}\right)$. The farm nutritional yield for nutrient $\mathrm{i}\left(\mathrm{Y}_{\mathrm{i}}\right)$ is a novel metric proposed by DeFries et al. (2015). This metric estimates for each nutrient the number of reference adults whose dietary reference intakes are entirely covered per year given an area and production. We used the same reference adult as in the nutritional functional diversity metric, although, any other age group, life stage, and sex could equally be used. The $Y_{i}$ values, calculated for the whole farm production, are divided by the farm area to facilitate comparability across contexts (i.e. number of reference adults ha ${ }^{-1}$ ). Finally, the nutrient deviation metric $\left(\mathrm{ND}_{\mathrm{i}}\right)$ assesses nutrient adequacy by comparing the availability of nutrient $i$ from consumed food from on- and off-farm sources against the household dietary requirement calculated from the dietary reference intakes given a household's demography and size (Ditzler et al. 2019). Negative deviations indicate a nutritional contribution that is lower than the household dietary requirements, whereas positive deviations indicate a surplus (see Appendix 1 for a detailed description of each metric).

\subsection{Study site}

The Son La province in the Northwest of Vietnam has emerged as an important agricultural region due to the intensified production of maize, rice and cassava (ILRI 2014). Despite poverty reductions and productivity increases, malnutrition continues to be a problem in the region. The percentage of children under five experiencing iron (Fe), vitamin A (Vit $\mathrm{A})$, calcium $(\mathrm{Ca})$, zinc $(\mathrm{Zn})$ and vitamin $\mathrm{C}$ (VitC) deficiencies continues to be relatively high (NIN 2012), with iron and vitamin A deficiencies above national averages (national values for deficiencies of $\mathrm{Fe}=29 \%$ and Vit $\mathrm{A}=14 \%$; NIN 2012).

The eco-region, characterized by the Tropical and Subtropical Moist Broadleaf Forests biome type (Olson et al. 2001), experiences a monsoonal climate where $92 \%$ of the yearly rainfall is concentrated between April and October (long-term average: $1309 \mathrm{~mm}$ season $^{-1}$; Hijmans et al. 2005), with limited precipitation from November to March (long-term average: $109 \mathrm{~mm}$ season $^{-1}$; Hijmans et al. 2005). The monsoonal rainy period is characterized by a warm climate (long-term average: $22-26{ }^{\circ} \mathrm{C}$; Hijmans et al. 2005), whereas temperatures around $15{ }^{\circ} \mathrm{C}$ are typical in the dry period, mainly from December to January.

The Doan Ket village, in Muong Bon commune (Mai Son district), is located in a mountainous region, $500 \mathrm{~m}$ above sea level, dominated by lowlands. The Doan Ket village is mainly composed of individuals from the Khinh ethnic group and was established in the 1960s as part of the resettlement from the Hoa Binh dam. The small village is relatively close to Hat Lot and Son La city, itis well connected with paved roads, and it reports extremely low population densities ( 1 person per $100 \mathrm{~m}$ in 2015; WorldPop 2013).

\subsection{Participatory selection of potential crop diversification strategies}

The research took place in the context of the CGIAR Research Program - (CRP) 'Integrated Systems for the Humid Tropics', a global programme aimed at supporting the intensification of integrated agricultural systems to improve the livelihoods of poor farming families, while guaranteeing ecosystems integrity in Asia, Africa, and the Americas. The Program was grounded in research for development through collaborative and participatory approaches (Hiwasaki et al. 2016). One of the interventions of the Humidtropics program in Vietnam focused on diversifying home gardens for income and nutrition security (Hiwasaki et al. 2016). In particular, homegarden diversification promoted nutritious crops with a potential for reducing nutritional gaps, while increasing the consumption of underrepresented foods in the local diet, 
including vitamin A-rich fruit and vegetables, dark green leafy vegetables, pulses, nuts and seeds (Van Hoi et al. 2015).

The selection of nutritious crops was conducted through a participatory process including stakeholders from different sectors (Van Hoi et al. 2015). The intervention focused on 15 out of the 30 nutritious crops selected (hereafter: 'Selected Crops') based on local consumer preferences and knowledge of agronomic potential (Van Hoi et al. 2015). Our modelling efforts considered ten Selected Crops with sufficient data including pulses (soybean [Glycine $\max (\mathrm{L}$.) Merr.]), vitamin A-rich fruits and vegetables (carrot [Daucus carota L.], papaya [Carica papaya L.], orange-fleshed sweet potato [Ipomoea batatas, Lam], pumpkin [Cucurbita pepo]), nuts and seeds (peanuts [Arachis hypogaea L.]), dark green leafy vegetables (mustard greens [Brassica juncea (L.) Czern.], water spinach [Ipomoea aquatica Forsk.]), in addition to other vegetables (French beans [Phaseolus vulgaris L.], and cowpeas [Vigna minima (Roxb.) Ohwi and Ohashi]) (See Table 3 for the plant parts consumed).

\subsection{Characterisation of the Doan Ket households and farming systems}

We surveyed eight farms (including 34 people above the age of six, and three babies under 12 months) in Doan Ket between November 2014 and September 2015. The farming systems and the dietary patterns in the village were characterised through a comprehensive survey. We used the IMPACTLite survey, a standardized tool used worldwide that facilitates collecting household information on key farmhousehold performance and livelihoods indicators (Rufino et al. 2013). The comprehensive and data-intensive survey collects information about the household structure, fields, cropping activities (yield, inputs and labour), livestock activities (production and labour), household expenditure and household-level food consumption (Rufino et al. 2013). As part of the survey, we only used one dietary recall to assess food consumption, therefore excluding seasonality of the foods consumed. The dietary recall recorded the foods consumed from on- and off-farm sources during the week prior to the interview (7-day dietary recall) with the approximate quantity (weight-kg or volume-lt) based on the memory of the interviewee. One focus group discussion with eight participants held in September 2015 complemented survey information on four topics: land-use mapping, crops cultivation (rotation and crop yields), dietary patterns and knowledge on nutritious crops.

We built a 'Baseline farm' in FarmDESIGN based on the eight farms surveyed in Doan Ket (Table 4). The Baseline farm includes the most common (i.e. representing $\geq 4$ farms) household size and demographics, farm components (fish pond, home garden, grassland areas, perennial fruit plants), cultivated crop species and the average self-reported values for farm size, crop species cultivation costs, household expenses and crop yields (Tables 3 and 4). The food consumption pattern for the household in the Baseline farm was generated using the most commonly consumed food items among farmers from on- and off-farm sources. We then calculated the mean and standard errors of the self-reported quantities for the most commonly consumed food items along with their selling and purchasing prices (Table 3; see Appendix 2 for a visual representation of the farm-household).

\subsubsection{Nutrition data}

We calculated the dietary reference intakes through the revised recommended dietary allowances for the Vietnamese population (Khan and Hoan 2008). We chose the revised recommended dietary allowances, since they were estimated for the Vietnamese population, whereas the available estimated average requirements were available for humans in general. The household nutrient requirement is the sum of each household member's requirement given their age group, gender and reproductive status (i.e., pregnant, lactating). The nutrients included in the modelling study were the dietary energy for moderate work category, vitamins (A retinol activity equivalent, C, Thiamine, Riboflavin, Niacin, B6, Folate, B12) and minerals (calcium, magnesium, iron [5\% bioavailability] and zinc [poor zinc absorption]). We used the 13 nutrients to calculate the functional diversity metrics $\left(\mathrm{NFD}^{\mathrm{P}}\right.$ and $\left.\mathrm{NDF}^{\mathrm{D}}\right)$, and Vit $\mathrm{A}, \mathrm{Ca}, \mathrm{Zn}$ and $\mathrm{Fe}$ to calculate nutrient deviations $\left(\mathrm{ND}_{\mathrm{i}}\right)$ and farm nutritional yield $\left(\mathrm{Y}_{\mathrm{i}}\right)$ metrics. The nutrient profiles for every food item commonly consumed among farmers (Table 3) mainly originate from the Vietnamese food composition table which provides nutrient contents per $100 \mathrm{~g}$ edible portion of raw ingredients (SMILING D.5-a 2013). We also used the USDA and the West African food composition tables in a few cases (USDA 2007; Stadlmayr et al. 2012). We considered potential nutrient losses due to cooking methods by using the USDA average retention factors values per food group (USDA 2016). We excluded condiments from the modelling effort. Foods in the Baseline farm and modelgenerated alternative farm configurations with quantities below $5 \mathrm{~g}$ person ${ }^{-1}$ day $^{-1}$ were excluded from the count- and abundance-based metrics. The selected cut off value is roughly double than the one used in the region to identify foodbased recommendations for Children (2.22 g children $^{-1}$ day $^{-1}$ ) (Ngoc Chau 2016).

\subsubsection{Baseline farm objectives, decision variables and constraints}

We used the multi-objective evolutionary algorithm in FarmDESIGN to explore options to improve the performance of the Baseline farm for six objectives (Tables 1, 3 and 4). The algorithm generates a set of alternative farm configurations 


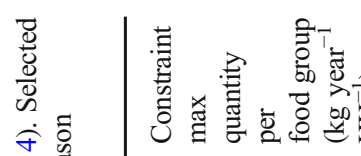

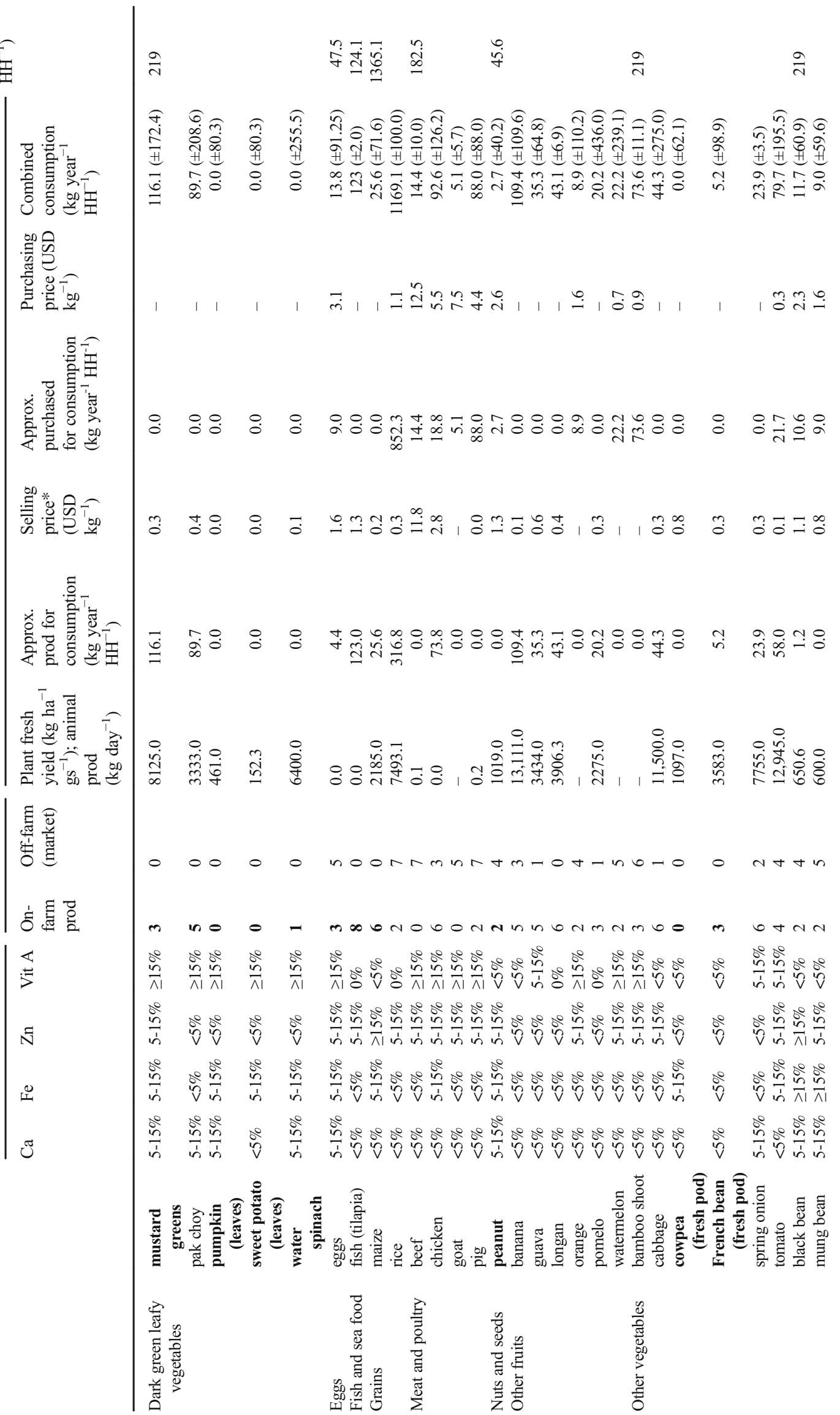




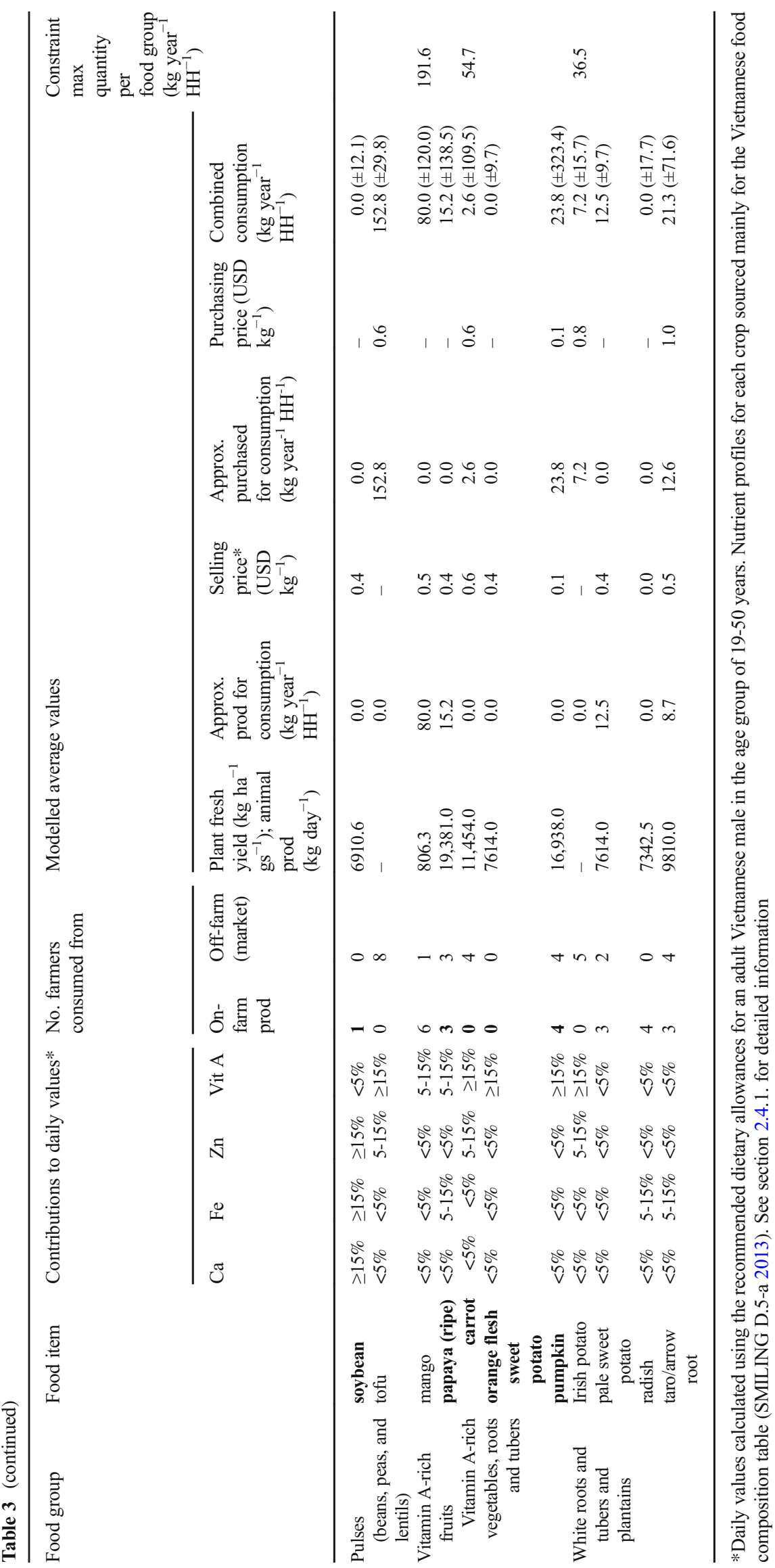




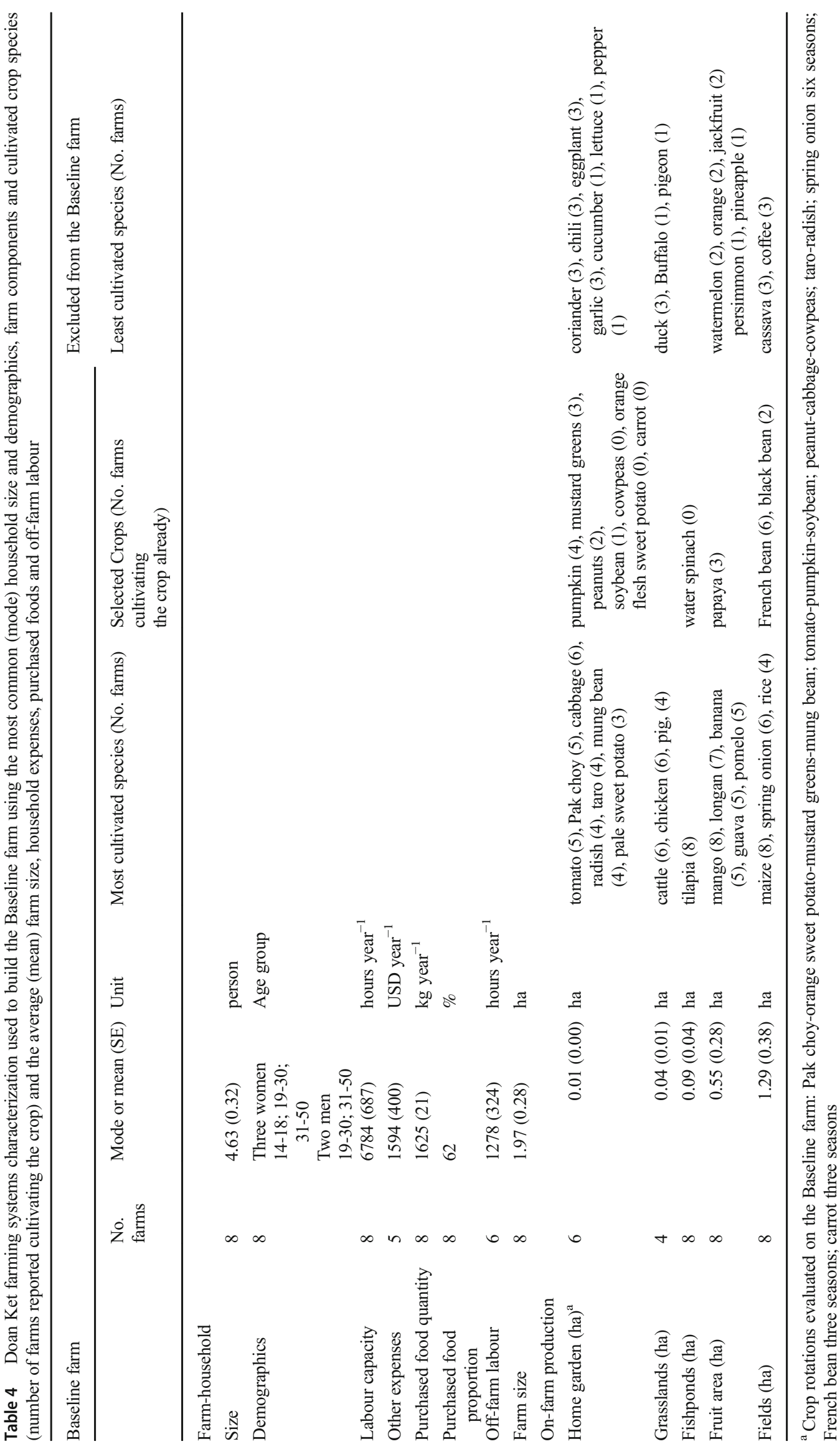


(solutions) that are iteratively improved using Pareto-based ranking (Groot et al. 2007, 2010, 2012; Groot and Rossing 2011). The objectives were to maximize the food supply (onand off-farm) necessary to satisfy the household dietary requirement, focusing on the four potentially deficient nutrients (Vit $\mathrm{A}, \mathrm{Ca}, \mathrm{Fe}$ and $\mathrm{Zn}$; the nutrient deviation $\mathrm{ND}_{\mathrm{i}}$ for each nutrient is an objective), while simultaneously improving household dispensable budget and household leisure time. Table 1 lists the objectives, decision variables, and constraints set in this modelling study. We configured FarmDESIGN optimization to yield 500 solutions after 1000 iterations to ensure stable outcomes.

\subsubsection{FarmDESIGN outputs - alternative farm configurations (solutions)}

We analysed the FarmDESIGN outputs at three levels. Firstly, we assessed the general trends of the 500-alternative farmhousehold configurations to identify trade-offs and synergies between the objectives. At this level, we looked at the food consumption patterns from on- and off-farm sources (diet) and from the Selected Crops only (intervention).

Secondly, we identified the indicators (see the list in Table 1) associated to alternative farm configurations with desirable (or undesirable) livelihood or nutritional outcomes. Alternative farm configurations with desirable livelihoods were those with a household dispensable budget and leisure time equal to or larger than in the Baseline farm (hereafter L+). For instance, $\mathrm{L}+$ farm configurations would potentially lead to a larger dispensable budget and leisure time for non-earning activities. Alternative farm configurations with desirable nutritional outcomes were those with positive nutrient deviations for $\mathrm{Ca}, \mathrm{Fe}$, Vit $\mathrm{A}$ and $\mathrm{Zn}$ (hereafter N+). Thus, $\mathrm{N}+$ farm configurations potentially set aside enough and more nutritious on- and off-farm food to satisfy household dietary requirements. Undesirable livelihood ( $\mathrm{L}-$ ) and nutrition $(\mathrm{N}-$ ) values indicate farm allocations yielding suboptimal configurations and resource allocations. We tested median statistical differences (at $p$ value $<0.05$ ) among groups of alternative farm configurations (i.e. $\mathrm{N}+\mathrm{L}+, \mathrm{N}-\mathrm{L}+, \mathrm{N}+\mathrm{L}-, \mathrm{N}-\mathrm{L}-$ ) through the Kruskal-Wallis test and the post-hoc Dunn's analysis (dunn.test package; Dinno 2017) in R (R Core Team 2016). Both tests are appropriate for unbalanced sample sizes.

Thirdly, we selected two contrasting farms from among the 500 alternative farm configurations to compare farm configurations and production for consumption in extreme situations. The 'Surplus farm' had the maximum positive nutrient deviations for the $\mathrm{Ca}$, Fe, Vit $\mathrm{A}$ and $\mathrm{Zn}$, and had a larger household dispensable budget and leisure time than the Baseline farm. On the contrary, the 'Deficit farm' had the lowest nutrient deviations across the four optimized nutrients and a lower household dispensable budget or leisure time than the Baseline farm.
Finally, we compared production diversity and diet diversity metrics across groups of alternative farm configurations using the Kruskal-Wallis test and the post-hoc Dunn's analysis. We identified the count- and abundance-based metrics measuring diversity in the diet or on the farm with significantly higher or lower values in the $\mathrm{N}+\mathrm{L}+$ and $\mathrm{N}+\mathrm{L}-$ groups of farms; farms theoretically satisfying household dietary requirements and leading to desirable nutritional outcomes.

\section{Results}

\subsection{Characteristics of the baseline farm}

Twelve food groups and 22 species from on- and off-farm sources were consumed in quantities above $5 \mathrm{~g}$ person ${ }^{-1}$ day $^{-1}$ by the household in the Baseline farm (Table 2). The Baseline farm set aside $12 \%$ of the whole on-farm production for household consumption, representing $47 \%$ of the total (on- and off-farm sources) foods consumed. The total household food cost was USD 2597 year $^{-1}$, which is $63 \%$ of the total income.

Large crop margins (USD 4864 year $^{-1}$ ) contributed to a positive household dispensable budget in the Baseline farm. French beans, maize and rice sales contributed to $84 \%$ of the crop margin $(51 \%, 24 \%$, and $9 \%$, respectively) with other contributions from vegetables (spring onion, tomato, Pak choi and cabbage) and fruits (longan, mango, banana, pomelo, papaya and guava). The on-farm production allowed only 77 days free from agriculture-related activities to each one of the four households' members working on the farm across the whole year (Figs. 3 and 4).

\subsection{Trade-offs and synergies among multiple objectives}

We found a trade-off between dispensable budget and household diet, and between dispensable budget and leisure time. Hence, increasing household dispensable budget would be associated with a decline in nutrient adequacy for satisfying household dietary requirements (lower $\mathrm{ND}_{\mathrm{i}}$ for all four nutrients; Fig. 3b, c, d, and e) as well as leisure time (Fig. 3a). In particular, nutrient deviations were drastically reduced where household dispensable budgets exceeded USD 6000 year $^{-1}$, i.e. three times more than in the Baseline farm (Fig. 3b, c, d, and e). Household leisure time was uncorrelated with the optimized nutrient deviations (Fig. 3f, g, h, and i). We found a synergetic increase in nutrient deviations with positive and significant correlations among all four nutrients. Nonetheless, the degree of increase in $\mathrm{ND}_{\mathrm{i}}$ varied among the nutrients, with increases in Vit A and Zn more easily attained than in $\mathrm{Ca}$ and $\mathrm{Fe}$ (Fig. 3j, k, 1, m, n, and o). This is likely linked to the fact that food items in the local diet (including 
Fig. 3 Relationships (Pearson's correlation coefficient and $p$ value) between the livelihood outcomes and nutritional outcomes. Livelihood outcomes are measured as the dispensable budget (available budget after expenditures) and, leisure time for non-earning activities. Nutritional outcomes are measured as the nutrient deviations of four likely deficient nutrients (Iron-Fe, ZincZn, Vitamin A-Vit A and Calcium-Ca) where positive deviations indicate the household yearly nutrient requirements were theoretically satisfied. The black square indicates the values for the Baseline farm, whereas other dots represent the alternative farm configuration colour-coded based on the nutritional and livelihood outcomes
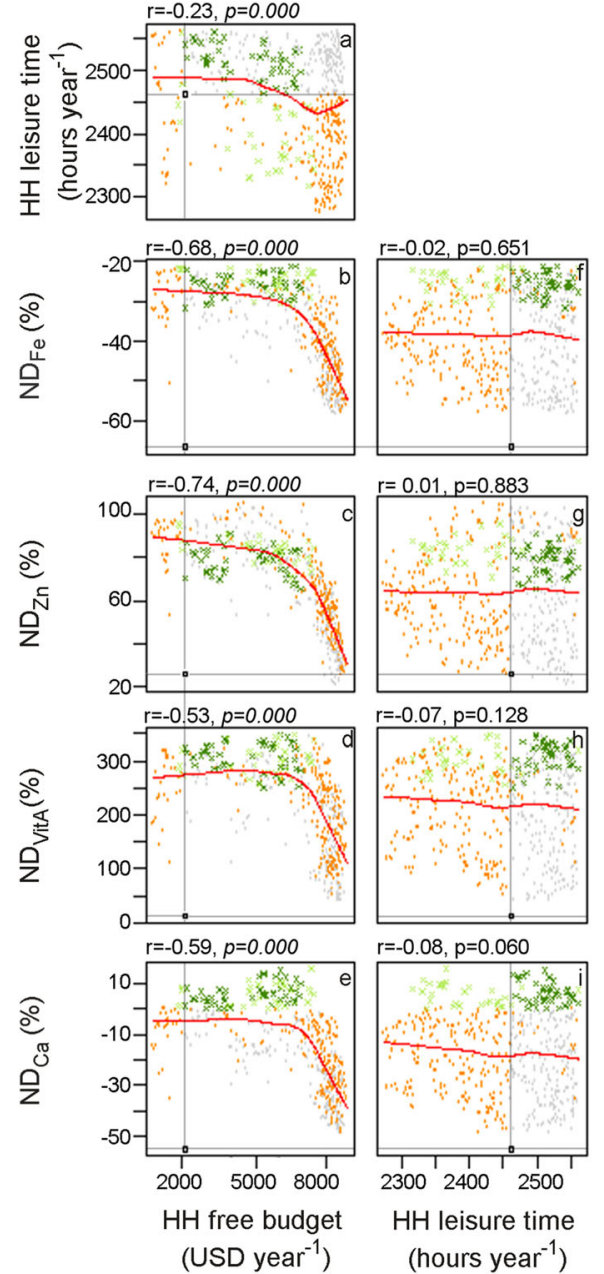

\begin{tabular}{|c|c|c|}
\hline \multirow[b]{3}{*}{ Liveliood outcomes } & \multicolumn{2}{|c|}{ Nutritional outcomes } \\
\hline & Undesired & Desired \\
\hline & $\begin{array}{c}1 \text { to } 2 \text { nutrient with } \\
\text { deviations }>0 \%\end{array}$ & $\begin{array}{l}3 \text { to } 4 \text { nutrient with } \\
\text { deviations }>0 \%\end{array}$ \\
\hline $\begin{array}{l}\text { Undesired } \\
\text { Leisure time or free budget } \\
<\text { Baseline farm ( } \text { ( })\end{array}$ & $\begin{array}{l}\text { oN-L-: Suboptimal } \\
\text { configurations }\end{array}$ & $\begin{array}{l}\times \mathrm{N}+\mathrm{L}-: \text { Better-off } \\
\text { nutrition }\end{array}$ \\
\hline $\begin{array}{l}\text { Desired } \\
\text { Leisure time \& free budget } \\
>=\text { Baseline farm ( } \square)\end{array}$ & $\begin{array}{l}\text { N-L+: Better-off } \\
\text { livelihoods }\end{array}$ & $\begin{array}{l}\times \mathrm{N}+\mathrm{L}+: \text { Win-Win } \\
\text { configurations }\end{array}$ \\
\hline
\end{tabular}

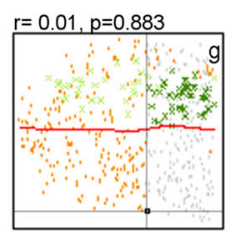

$r=-0.07, p=0.128$

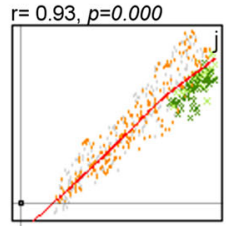

$r=0.72, p=0.000$

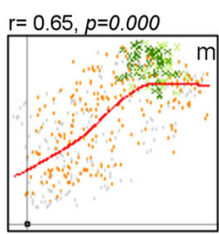

$r=0.75, p=0.000$

$r=0.89, p=0.000$

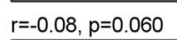

$r=0.89, p=0.000$
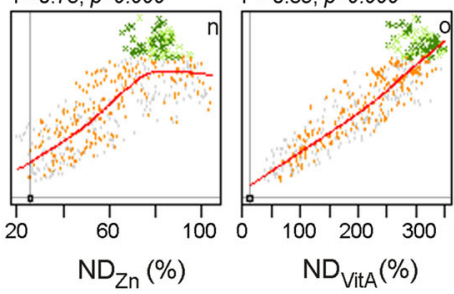

Selected Crops) more commonly contribute to the daily nutritional requirements for $\mathrm{Vit} \mathrm{A}$ (ten food items) and $\mathrm{Zn}$ (six food items) than $\mathrm{Fe}$ (three food items) and $\mathrm{Ca}$ (one food item) (Table 3).

Only a few alternative farm configurations ( $8 \%$ of configurations, 46 farms) achieved simultaneous improvements in both nutrition and livelihoods $(\mathrm{N}+\mathrm{L}+)$, farm configurations potentially representing win-win situations. An additional 7\% of the configurations ( 31 farms) yielded desirable nutritional improvement although they reduced household dispensable budget or leisure time $(\mathrm{N}+\mathrm{L}-)$. The remaining $85 \%$ of the configurations (423 farms), yielded undesirable nutritional outcomes where $\mathrm{Ca}$ and $\mathrm{Fe}$ requirements were unmet, resulting in negative $\mathrm{ND}_{\mathrm{Ca}}$ and $\mathrm{ND}_{\mathrm{Fe}}$ (Fig. 31).

\subsection{Contribution of selected crops to livelihoods and nutrition}

The quantity of Selected Crops produced and set aside for consumption is a better indicator for measuring nutritional contribution than the area allocated to Selected Crops. Our modelling study suggests that the farm-household configurations where a quantity of the Selected Crops produced are set aside for home consumption (e.g. Surplus farm) allowed the household to attain its nutritional needs, whereas farmers planting larger areas with the Selected Crops (e.g. Deficit farm) and not setting aside produce for consumption (selling it instead) failed to attain their nutritional needs (Fig. $4 \mathrm{a}$ and d). We found that the deviations for $\mathrm{ND}_{\mathrm{V}_{\mathrm{itA}}}$ and $\mathrm{ND}_{\mathrm{Zn}}$ drastically increased from slightly larger than zero in the Baseline farm to a surplus of $100 \%$ to $200 \%$ in the alternative farms. This suggests a twofold or larger increase in the supply of those nutrients than what the household requires. $\mathrm{Fe}$, however, would remain insufficient (20\% below the household requirements) regardless of the food consumed from onand off-farm sources (Fig. 3j, k, and l) or the quantity of the Selected Crops' production set aside for consumption (Fig. 4d); and despite the current consumption of fish and seafood, and meat and poultry (Table 3, Appendix 3). If the farm-household set aside $>700 \mathrm{~g}_{\text {person }}{ }^{-1}$ day $^{-1}$ of the production of Selected Crops for consumption it could theoretically satisfy their calcium needs (positive deviations), given the modelling assumptions (Fig. 4b; Table 3). Although the Selected Crops represent five different food groups, including dark green leafy vegetables, nuts and seeds, other vegetables, pulses, vitamin A fruits, and vitamin 
Fig. 4 Values for the seven maximized objectives across alternative farm configurations given the area allocated to planting the Selected Crops in the home garden and the quantity of Selected Crops production set aside for household consumption. Nutrient deviations for vitamin A (Vit A), zinc $(\mathrm{Zn})$, calcium $(\mathrm{Ca})$ and iron $(\mathrm{Fe})(\mathbf{a}, \mathbf{b})$, household (HH) dispensable budget (c, d) and household leisure time $(\mathbf{e}, \mathbf{f})$. Each point represents an alternative farm configuration

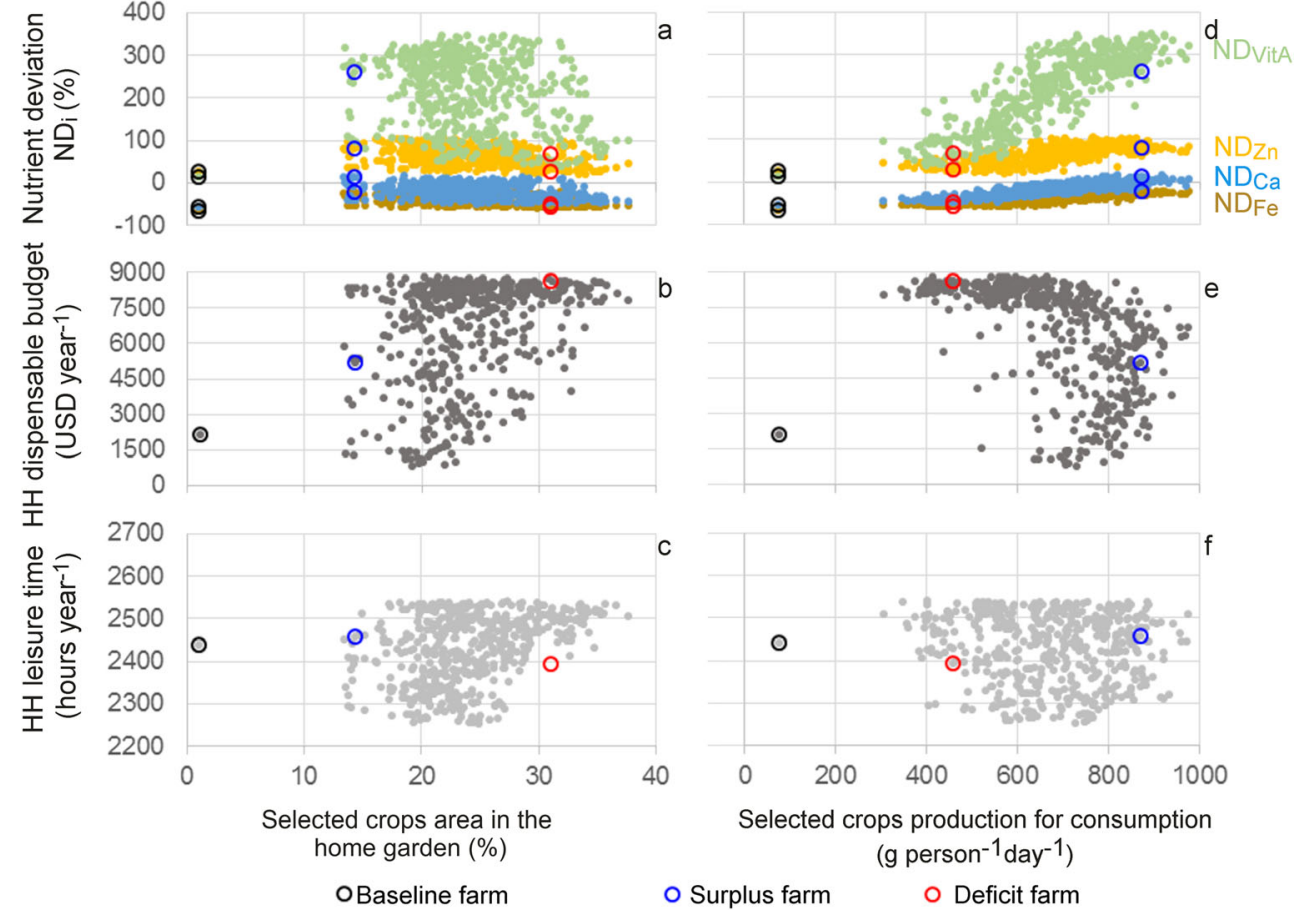

in significantly larger contributions from on-farm (including larger proportion of Selected Crops production set aside for household consumption) and significantly smaller crop gross margins from selling on-farm production in $\mathrm{N}+\mathrm{L}+$ and $\mathrm{N}+\mathrm{L}-$ farm configurations (Figs. 5b-d). In the latter farms, the household food cost represented around $67 \%$ of the total income, suggesting that satisfying household dietary requirements demands incurring substantial costs (Fig. 5e).

However, the total food costs in $\mathrm{N}+\mathrm{L}+$ and $\mathrm{N}+\mathrm{L}-$ alternative farms was only 1.1 times larger than in the Baseline farm due to the increased crop gross margin, whereas the total food consumption from on- and off-farm sources was 1.7 times more in $\mathrm{N}+\mathrm{L}+$ and $\mathrm{N}+\mathrm{L}-$ alternative farms compared to the Baseline farm (Fig. 5a and e). This suggests that the income generated from selling some of the production of the Selected Crops with high market value could potentially contribute to covering the cost of achieving desirable nutritional outcomes (Fig. 5b).

Although the optimization excluded environmental objectives, our results suggest that organic matter from crop residues was significantly larger in $\mathrm{N}+\mathrm{L}+$ and $\mathrm{N}+\mathrm{L}-$ alternative farms, yet lower than the Baseline farm (Fig. 5i), indicating a likely negative effect on soil quality after home garden diversification with the crops selected using a participatory approach.

\subsection{Comparison of nutrition-related metrics}

Alternative farm configurations significantly increased the onfarm production diversity for consumption in relation to the Baseline farm (Fig. 6). Farms with desirable nutritional out-

comes $(\mathrm{N}+\mathrm{L}+$ and $\mathrm{N}+\mathrm{L}-$ farms $)$, meaning the farms that
Farm configurations with desirable nutritional outcomes (i.e. $\mathrm{N}+\mathrm{L}+$ and $\mathrm{N}+\mathrm{L}-$ ) originated from increasing food consumption mainly from on-farm production rather than from off-farm sources such as the market (Fig. 5a, d and g). This was reflected 

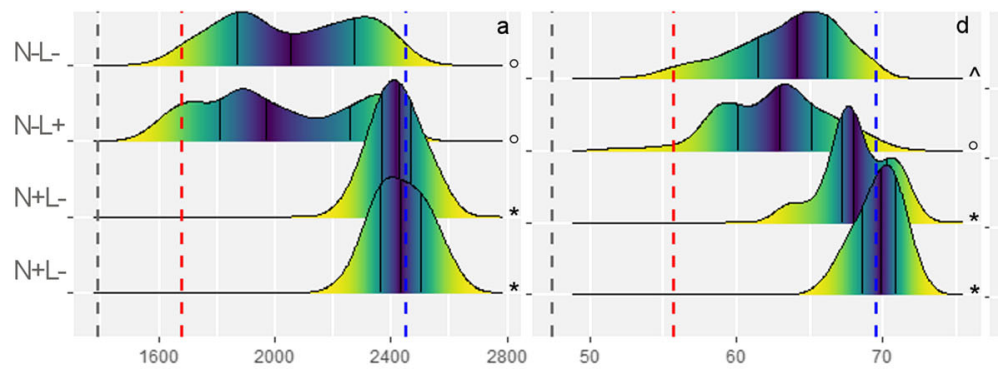

Food consumption (g person-1 day-1)

On-farm consumption (\%)
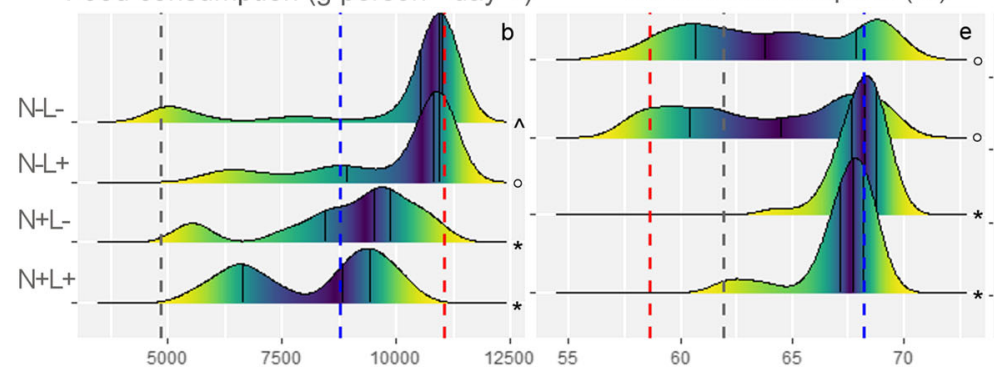

Crop gross margin (USD year-1)

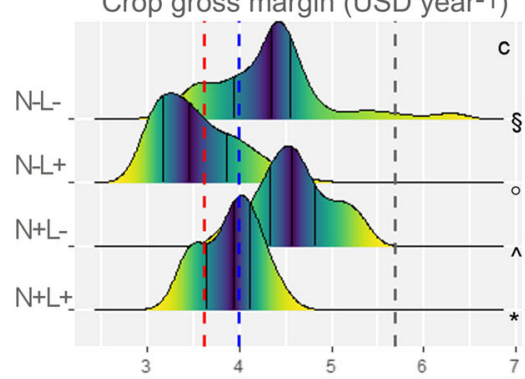

HG - Farm area (\%)

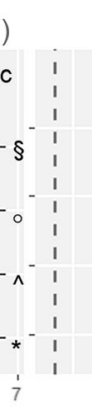

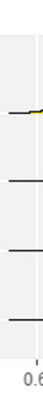

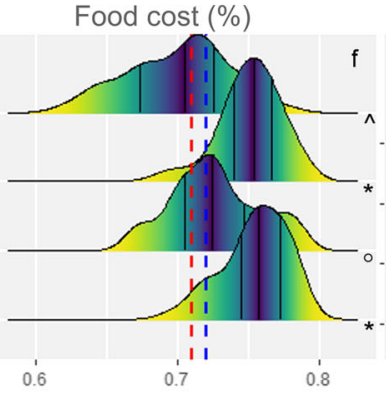

$\mathrm{HHG}$

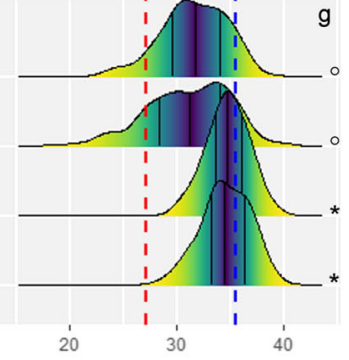

SC consumption (\%)

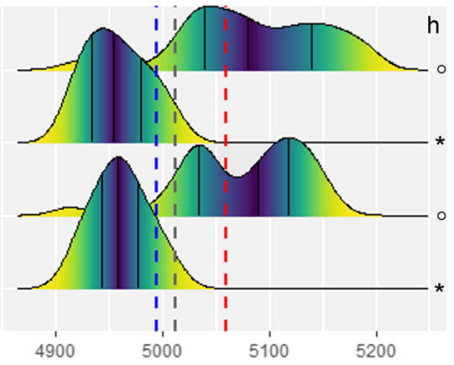

Crop labor (hours year-1)

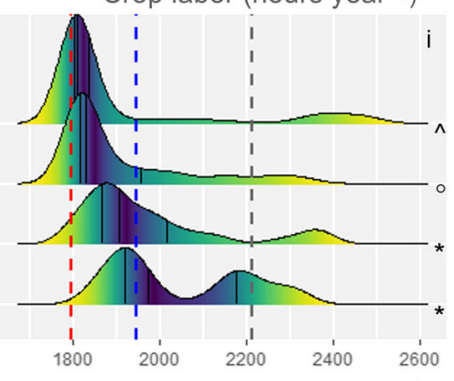

OM crop residues (kg yr-1)

- - Baseline farm --- Surplus farm

- Deficit farm

$\begin{array}{llll}0 & 0.1 & 0.3 & 0\end{array}$

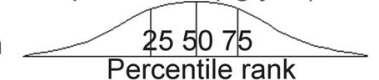

Fig. 5 Range of variability across indicators and grouped alternative farm configurations with desirable $(+)$ or undesirable $(-)$ Nutritional $(\mathrm{N})$ or Livelihood (L) outcomes. The different symbols along the right-hand vertical axis indicate significant differences among groups (Post-hoc

could satisfy the household dietary requirements for at least three nutrients (Vit A, Ca and $\mathrm{Zn}$ ), scored significantly larger median values for the metrics $\mathrm{NFD}^{\mathrm{D}}, \mathrm{NFD}^{\mathrm{P}}, \mathrm{H}^{\mathrm{D}}, \mathrm{D}^{\mathrm{D}}$ (Fig. $6 \mathrm{~b}$, $\mathrm{g}, \mathrm{h}$ and i). The abundance metrics, $\mathrm{H}^{\mathrm{P}}$ and $\mathrm{D}^{\mathrm{P}}$, were not significantly different among farm groups when measuring on-farm production diversity for household consumption, although most of the $\mathrm{N}+\mathrm{L}+$ farms tended to have larger $\mathrm{H}^{\mathrm{P}}$ values (Fig. 6c and d). This suggested that in this context, the functional diversity metrics (a more recently proposed metric) tend to capture the contribution to household dietary requirements better than richness and abundance metrics when measuring on-farm production diversity.

Measuring the nutrient yield for the whole production could lead to misguiding results. The $Y_{i}$ metric, which captures the contribution of the whole farm production (e.g. food produced for animal feed), indicated that increasing the number of reference adults with covered yearly dietary reference intakes for $\mathrm{Y}_{\mathrm{Zn}}$ reduced the number of reference adults with covered yearly
Dunn's test significance at $p$ value $<0.05$ ). $\mathrm{SC}=$ Selected Crops, $\mathrm{OM}=$ organic matter, $\mathrm{HG}=$ home garden (including Water Spinach area in the Fishpond), H Shannon index. Dark blue areas indicate mean values along the distribution of the alternative farms (points)

dietary reference intakes for $\mathrm{Y}_{\mathrm{Ca}}, \mathrm{Y}_{\mathrm{Fe}}$ and $\mathrm{Y}_{\mathrm{VitA}}$ (Fig. 6j, k, 1, and $\mathrm{m}$ ). The large contributions on Zinc were linked to maize, which contributes $>15 \%$ of the daily values for this nutrient. Yet maize production is mainly used to feed the livestock and is not consumed by household members as part of their daily diets (Table 1). Likewise, the nutrient yield results indicate that the whole farm production could satisfy the Fe dietary reference intakes for $\sim 25$ reference adults $\left(\mathrm{Y}_{\mathrm{Fe}}\right)$ on average in $\mathrm{N}+\mathrm{L}+$ and $\mathrm{N}+\mathrm{L}-$ farms although the nutrient deviation indicated $\left(\mathrm{ND}_{\mathrm{Fe}}\right)$ household Fe requirements remained unmet $\left(\mathrm{ND}_{\mathrm{Fe}}\right)$ (Figs. 61 and 3d). The large $\mathrm{Y}_{\mathrm{Fe}}$ values were linked to unfeasible consumption levels for Fe (e.g. $1057 \mathrm{~g}$ of maize in a day to satisfy Fe daily requirements). For instance, we found that using $Y_{i}$ on only one nutrient can also lead to misguiding conclusions, since farms with desirable nutritional outcomes $(\mathrm{N}+\mathrm{L}+$ and $\mathrm{N}+\mathrm{L}-)$ included farm configurations where the trade-off among nutrients was minimized with significantly smaller median values for $\mathrm{Ca}$ 


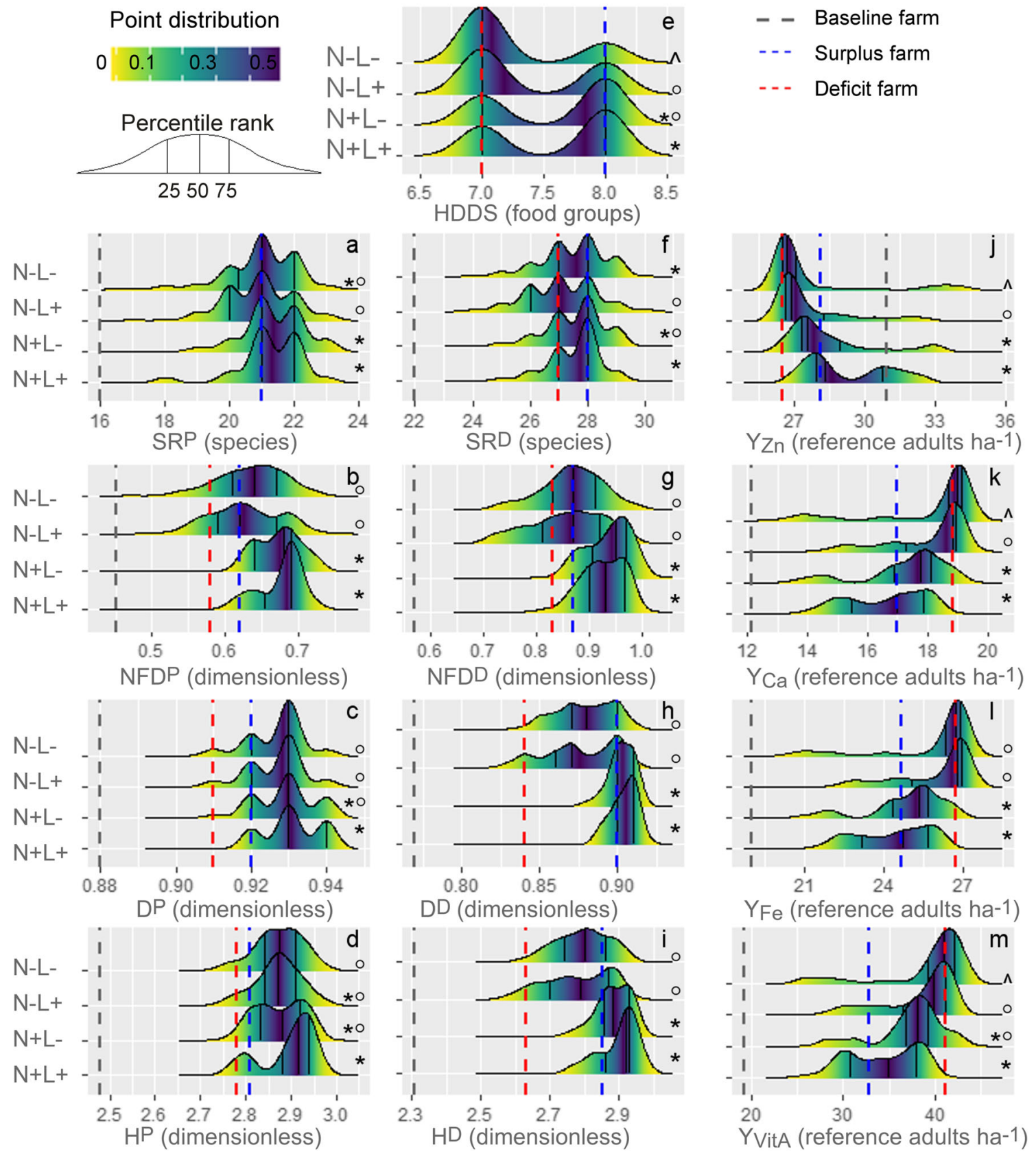

Fig. 6 Range of variability across human nutrition metrics values and grouped alternative farm configurations given desirable $(+)$ or undesirable (-) Nutritional (N) or Livelihoods (L) outcomes. Different symbols indicate significant differences among groups (Post-hoc Dunn's test significance at $\mathrm{p}$ value $<0.05)$. Diet $\left({ }^{\mathrm{D}}\right)$ metrics consider on- and off-

farm sources of food for household consumption, whereas production $\left({ }^{\mathrm{P}}\right)$ metrics only consider on-farm production for household consumption. Refer to Fig. 2 for metrics' description (see also Appendix 1). Dark blue areas indicate mean values along the distribution of the alternative farms (points)

and $\mathrm{Fe}$, and significantly larger median values for $\mathrm{Zn}$ in particular (Fig. 6j, k, and l).

\subsection{The surplus and deficit alternative farms: Sell it or eat it?}

The selected extreme farm configurations of Surplus and Deficit showed potentially contrasting pathways for home garden diversification in the Doan Ket context. The Surplus

farm exemplified a farm configuration leading to a win-win situation where both nutrition and livelihoods would be improved (hence an $\mathrm{N}+\mathrm{L}+$ farm). There was an improvement in both dimensions despite the large contribution of on-farm production for household consumption and the large food cost (Fig. 5a, d, g, and e). Home garden area and crop area evenness $\left(\mathrm{H}_{\mathrm{HG}}\right)$ were similar in both Surplus and Deficit farms. (Fig. 5f). Nonetheless, the larger crop labour required in the 
Deficit farm is likely linked to the larger areas planted with carrots and French beans (Figs. 5h and 7).

The Deficit farm is the extreme example of a farm configuration maximizing income over nutritional contribution and even choosing a cheaper diet than in the Baseline farm (hence an N-L- farm) (Fig. 5a, d, and g). For example, the food cost in the Deficit farm represents $59 \%$ of the total farm-household expenditures, whereas the Baseline Farm and Surplus farm had larger values (62\% and 68\% respectively) (Fig. 5e). Despite the lowest food cost in the Deficit farm, it set aside a larger quantity of food for consumption from on- and offfarm sources of $1683 \mathrm{~g}$ person ${ }^{-1}$ day $^{-1}$ compared to the Baseline farm (1393 g person ${ }^{-1}$ day $\left.^{-1}\right)$, yet less than the Surplus farm (2454 g person ${ }^{-1}$ day $\left.^{-1}\right)$. The Surplus farm consumed an extra food group (HDDS) and one additional species $\left(\mathrm{SR}^{\mathrm{D}}\right)$ with more even distributions among food items $\left(\mathrm{H}^{\mathrm{D}}, \mathrm{D}^{\mathrm{D}}\right)$ and larger functional diversity $\left(\mathrm{NFD}^{\mathrm{D}}\right)$ than in the Deficit farm (Fig. 6e, f, g, h, and i). The differences in production diversity were smaller, where the Surplus farm had the same number of species for consumption $\left(\mathrm{SR}^{\mathrm{P}}\right)$, slightly larger functional diversity $\left(\mathrm{NFD}^{\mathrm{P}}\right)$ and larger evenness crop production for consumption $\left(\mathrm{H}^{\mathrm{P}}, \mathrm{D}^{\mathrm{P}}\right)$ than the Deficit farm (Fig. 6a, b, $\mathrm{c}$, and $\mathrm{d}$ ). This modelling study shows how measuring diversity only on the production side $\left(\mathrm{SR}^{\mathrm{P}}, \mathrm{NFD}^{\mathrm{P}}, \mathrm{H}^{\mathrm{P}}, \mathrm{D}^{\mathrm{P}}\right)$ is therefore limited and not suitable for measuring the nutritional contribution of NSA interventions. The production diversity metrics are particularly limited in the cases where farmhouseholds opt for selling their diversified production rather than consuming it.

The larger crop gross margins in the Deficit farm originated from the sale of mostly the Selected Crops such as water spinach (dark green leafy vegetables), soybeans (pulses), cowpeas and spring onions (other vegetables) (Fig. 7). The areas under cultivation for those crops were similar in both farms. Nonetheless, the quantity of Selected Crops' production set aside for household consumption was at least four times smaller in the Deficit farm than in the Surplus farm (Fig. 7). Other sold crops had larger planted areas in the Deficit farm than in the Baseline and the Surplus farms, yet consumption remained similar or lower (i.e. Selected Crops: carrot, French
Fig. 7 Changes between the Baseline farm (zero X-axes) and the Surplus and Deficit farms. * indicates Selected Crops. Papaya areas in the Surplus farm = $3521 \mathrm{~m}^{2}$ and the Deficit farm $=$ $5425 \mathrm{~m}^{2}$

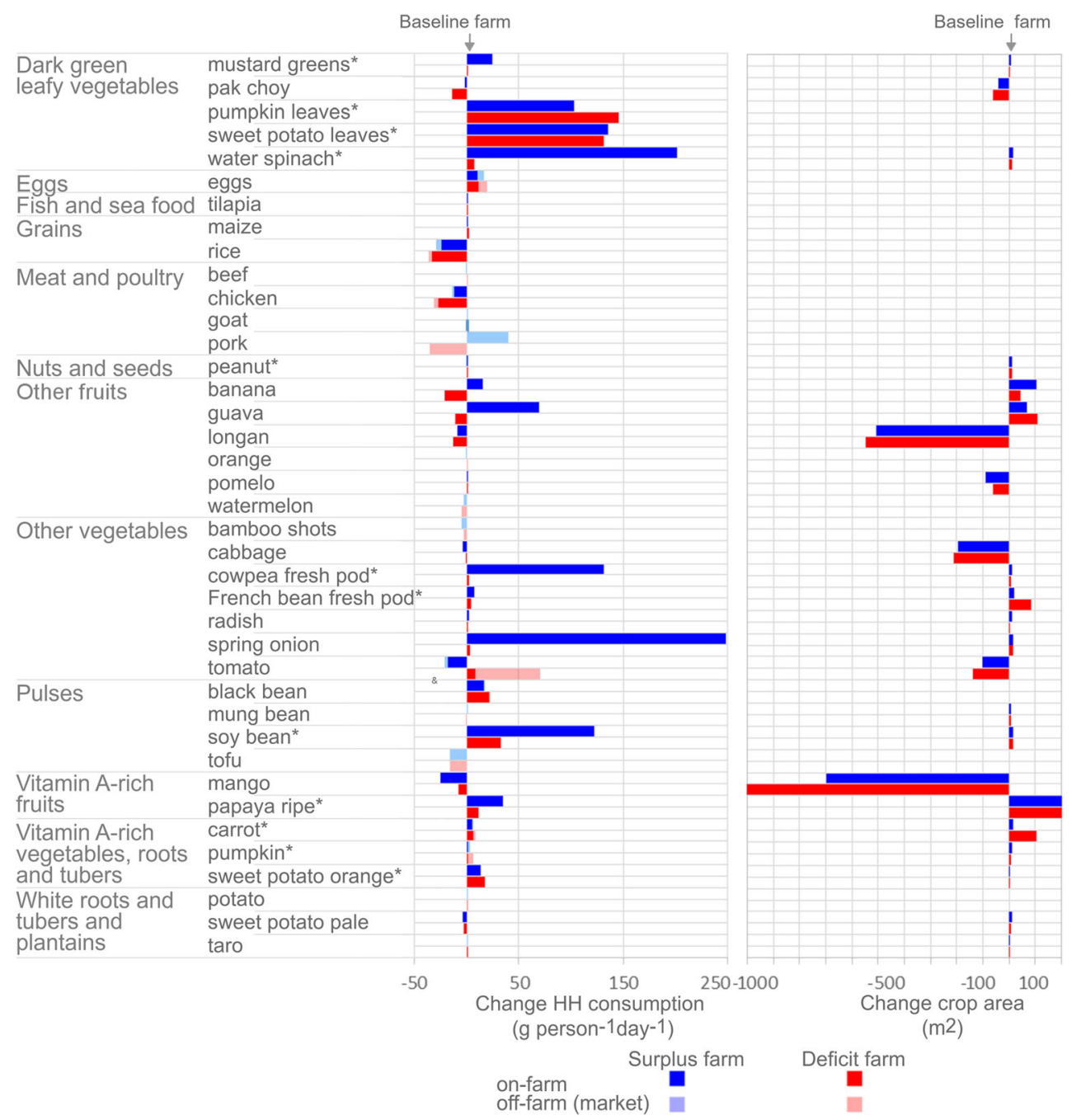


and guava). The Deficit farm reduced meat and poultry consumption from the on-farm (chicken) and off-farm (pork) sources (Fig. 7). The Deficit farm also reduced the consumption of other fruits (banana and guava) from on-farm production, while it increased the consumption of other vegetables (mainly tomato) from off-farm sources. The reduced tomato area planted and the increment in the quantity of tomato purchased reflected that buying tomato was cheaper than producing it in the Doan Ket and modelling context (Fig. 7).

The Surplus farm increased its production for household consumption of most of the Selected Crops, except for peanuts and pumpkin, which remained aligned with the number of Selected Crops set aside in the Baseline farm (Fig. 7). The Surplus farm increased its consumption of other fruits (guava and banana) and other vegetables (mostly cowpea and spring onion), while it reduced consumption of tomato from on-farm production. Contrary to the Deficit farm, the Surplus farm increased its consumption of pork (Fig. 7).

The area planted to Papaya (vitamin A-rich fruits) expanded greatly in both Deficit and Surplus farms, occupying almost the whole fruit area in the Deficit farm (0.54 ha) albeit with quantities set aside for household consumption that were nonetheless three times smaller than in the Surplus farm (Fig. 7). Ripe papaya has the highest values for the optimized nutrients $(\mathrm{Ca}, \mathrm{Fe}$ and $\mathrm{Vit} \mathrm{A})$ among the farm perennial fruit plants, hence the preference to plant such large papaya areas across all alternative farm configurations. Papaya, banana and guava cultivation areas expanded at the expense of mango, longan and pomelo areas. In both farm configurations (Deficit and Surplus) compared to the Baseline farm, tofu (a refined soybean product sourced off-farm) consumption reduced whereas soybean consumption from on-farm production increased due to soybeans larger content of the optimized nutrients and lower cost.

\section{Discussion}

The global commitment to end malnutrition through nutritionsensitive agriculture (NSA) requires the use of robust methods, models, and metrics that disentangle the complex relationship between agriculture- and nutrition (Herforth and Ballard 2016). The use of whole farm-household models enables ex-ante assessments of the potential trade-offs and challenges that NSA interventions could pose to a farm-household. Farm-household models also enabled us to estimate the potential contribution of agricultural interventions towards satisfying household dietary requirements and improving household livelihoods. In this study we showed the applicability of the new 'Household Nutrition' module included in the expanded FarmDESIGN model for estimating several metrics linked to diet and nutrition. We discuss how the exante analysis could facilitate designing NSA interventions while exploring potential intervention (i.e. home garden diversification) pathways. Lastly, we discuss how FarmDESIGN facilitates testing the robustness of the different metrics linking on-farm production and household dietary requirements in agriculture-nutrition projects.

\subsection{NSA interventions and potential development pathways}

Interventions such as home-garden diversification are common in Vietnam. Starting in 1986, the Vietnamese government actively promoted these interventions under the Doi Moi policy; the Garden-Pond-Livestock system (VAC: Vuon-Ao-Chuong in Vietnamese) (Luu 2001). The VAC system contributes between 30 and $60 \%$ of the total household income (Trinh et al. 2003). In North Vietnam, home-garden production contributes on average $13 \%$ of the household total income (Trinh et al. 2003), which is in line with the $16 \%$ estimated for the Baseline farm in this modelling study. Nonetheless, food production for household consumption from the diversified farming system is insufficiently contributing to the nutrient deficiencies identified in the Baseline farm and reported in the general nutrition survey 2009-2010 (NIN 2012). Likewise, maximizing income generation over nutrition is a trend reported in the study region where home gardens are transitioning from subsistence-oriented towards more profitable and commercial oriented home gardens, reducing species diversity and limiting the contribution to household nutrition (Mohri et al. 2013). Implementing an NSA intervention in this region thus demands careful planning to maximize the likelihood of adoption, and to avoid the likely negative consequences of such interventions (e.g. reductions in organic matter from crop residues), as indicated by this modelling study.

Crop diversification in the home gardens in tandem with other activities such as promoting other naturally occurring vegetables and educational and promotional interventions could increase the successful adoption of the Selected Crops for desirable nutritional outcomes and better livelihoods. The participatory selection and promotion of nutritious crops is novel in the area and responds to the expectation and interest of the community. Although, promoting other naturally occurring vegetables in the region with larger nutritional contributions (Ogle et al. 2001) could help to fill the nutritional gaps of the Selected Crops (e.g. low iron or calcium contributions). Empirical evidence in Bangladesh indicates the feasibility of tripling home garden production and vegetable consumption (Ferdous et al. 2016). In this modelling study we estimated that improving household nutrient adequacy could be reached by almost doubling on-farm contributions to household consumption, although the large consumption of the Selected Crops for nutritional outcomes (i.e. calcium - Ca) remains to be tested. For instance, increasing the consumption will 
require changes in both crop production and consumption behaviour and preferences to make the most of the nutrient potential of the new or underutilized Selected Crops (e.g. pumpkin and sweet potato leaves, orange flesh sweet potato). Hence there appears to be a key role to be played by educational and promotional interventions (Berti et al. 2004; Ruel and Levin 2000).

Working with the communities on food preferences and nutrition awareness could help farmers to soften the trade-off between nutrition and income. For example, this modelling study confirms that the market opportunity of the Selected Crops (e.g. large crop gross margin) could help to cover the larger food costs linked to desirable nutritional outcomes. This is in line with Greiner (2017) who found that a food-based approach $^{1}$ is a cost-efficient strategy to improve nutritional status, particularly in areas where multiple nutrients are deficient. Nonetheless, our results also suggest that home-garden diversification could also lead to maximize income generation rather than nutritional outcomes, as is already the case in the area. Maximizing income does not necessarily result in more and nutritious food available from the market. For example, despite the diversity of food items outsourced from the market (18 food items) in the Baseline farm, the alternative farm configurations seldom reduced the on-farm production for household consumption to replace these with food from the market. On the contrary, few food items outsourced from the market were replaced by on-farm production due to larger nutrient content and lower cost in the modelling study. This suggests that only improving market access for subsistence farms as a promising livelihood and development strategy as suggested by Sibhatu and Qaim (2018) could be limited and context-dependent.

\subsection{Robustness of metrics for comparability across NSA interventions}

A wide range of metrics is commonly used to assess dietary diversity and on-farm production diversity (Herforth and Ballard 2016; Sibhatu and Qaim 2018). The linkages or associations between dietary and on-farm production diversity are analysed using different metrics and at different scales (e.g. Berti 2015; Sibhatu et al. 2015). Therefore, the need for systematic assessment of the robustness and applicability of the different metrics under different contexts, scales and socioecological settings is increasingly recognized (Powell et al. 2015; Herforth and Ballard 2016). Identifying agreed-upon and robust metrics to measure nutritional outcomes at the farm-household level will allow comparability across NSA interventions and contexts.

In this modelling exercise, we compared diverse and commonly used metrics in NSA interventions across farm

\footnotetext{
${ }^{1} \mathrm{http}: / / w w w . f a o . o r g / a g / a g n /$ nutrition/household_food_en.stm
}

configurations and food allocations for household consumption from on- and off-farm sources. We compared the metrics values against the nutrient deviation; a theoretical assessment of the contribution to household dietary requirements. We found that the usefulness of $\mathrm{SR}^{\mathrm{D}}$ was limited in the context of Doan Ket even though it was proposed as an appropriate metric for measuring food diversity in individual diets and nutritional adequacy of diets (Lachat et al. 2017). The $\mathrm{SR}^{\mathrm{D}}$ and the HDDS performed poorly given the non-significant differences between farms that could and could not satisfy the household dietary requirements for vitamin A, calcium and zinc. It is important to note that household-level metrics of diet are often associated with household food access, rather than dietary quality, and hence nutrition of individuals which might explain the poor performance of $\mathrm{SR}^{\mathrm{D}}$ which was validated as an individual, rather than a household-level indicator. We found that other metrics such as functional diversity and Shannon's and Simpson's diversity indexes for the household diet (on- and off-farm sources) $\left(\mathrm{NFD}^{\mathrm{D}}, \mathrm{H}^{\mathrm{D}}, \mathrm{D}^{\mathrm{D}}\right.$ ) performed better at predicting desirable nutritional outcomes in Doan Ket. All those metrics scored significantly higher median values among farm configurations with desirable nutritional outcomes $(\mathrm{N}+)$.

On the contrary, only one metric measuring on-farm production diversity for consumption, the nutritional functional diversity $\left(\mathrm{NFD}^{\mathrm{P}}\right)$, was significantly larger in farms with desirable nutritional outcomes. Functional diversity metrics have been proposed recently to measure production diversity (e.g. Remans et al. 2011; DeClerck et al. 2014), whereas richness and abundance metrics to measure production diversity are used more commonly (See Appendix 1). Hence, the NFD ${ }^{\mathrm{P}}$ seems a promising metric that needs to be tested in a wider range of farm-household contexts. Our results also support that $\mathrm{H}$ tends to be more sensitive to rare species than $\mathrm{D}$ (Peet 1974). For instance, H could be more appropriate in cases where diets and on-farm production are dominated by "rare" species and food items.

The farm nutritional yield $\left(\mathrm{Y}_{\mathrm{i}}\right)$ metric is a novel metric able to capture the balanced production of nutrients. It does, however, require careful interpretation if the destination of the produced food is unknown or if analysed only for one nutrient. The $Y_{i}$ metric considers the whole farm production, which could bias the real contribution to human and household nutrition. Similarly, greater $Y_{i}$ values for a certain nutrient could be misleading, since we found that farm configurations with desirable nutritional outcomes had greater $\mathrm{Y}_{\mathrm{Zn}}$ values and lower $\mathrm{Y}_{\mathrm{Ca}}, \mathrm{Y}_{\mathrm{Fe}}$, and $\mathrm{Y}_{\mathrm{VitA}}$ values than farm configurations with sub-optimal nutritional outcomes.

\subsection{Study limitations}

This modelling study is supported by an intense data collection aiming to capture farming systems and food consumption 
across eight households in Doan Ket. Data collection was part of the pilot phase of the project in order to test the effectiveness of the intervention and guide it rather than to inform policy recommendations. Therefore, the Baseline farm properly represents a considerable portion of farm-households in the village, yet the results from this modelling study ignore other farm-household types that are less common in the area with production systems dominated by the excluded crops (e.g. coffee or cassava; Table 1). A larger sampling effort is therefore suggested for a more comprehensive characterization of the impact of the intervention across the diverse farmhousehold types that characterise the region. Similarly, the available food consumption data for Doan Ket was particularly limited since it is based on one weekly dietary recall, which is more subjective to recall error (Kennedy et al. 2011). Nonetheless, our comparison with the regional averages indicates similar consumption levels at the food group level (See Appendix 3). The 'Human Nutrition' module is potentially overestimating consumption or nutrient intake since food waste is currently not being captured by FarmDESIGN. Another inherent limitation of the model is the yearly analysis, which underestimates issues related to seasonal food availability, food price seasonality and intra-household food distributions.

Despite the considerable efforts in collecting accurate data, the modelling effort is potentially underestimating the species richness in on-farm production and household diets. For example, ethnobotanical studies identified 38.6 species on average per home harden in Northern Vietnam (Vlkova et al. 2011). Identifying home garden species through food or crop recalls may ignore other important crop and varietal species used for household consumption, as well as species used for other purposes such as medicine, firewood, fodder, materials for construction or crafts (Sêdami et al. 2017; Vlkova et al. 2011). Despite these limitations, here we show how the expanded FarmDESIGN model facilitates measuring the impact of interventions by easily looking at the whole system (e.g. diets), a subset of the system (e.g. Selected Crops) and at alternative farm-household configurations with contrasting strategies for predicting likely farm-household trajectories. Besides the wide range of performance indicators across farm-household domains, which facilitates measuring unexpected impacts (e.g. reduction on leisure time) and the calculation of different metrics commonly used in NSA.

\section{Conclusion}

We applied a farm-household model to evaluate the effects of a nutrition-sensitive agriculture (NSA) intervention (i.e. home-garden diversification) on representative farming households from Doan Ket, Vietnam. FarmDESIGN facilitates estimating the potential contribution of an intervention towards attaining household nutritional needs. Capturing performance indicators (and their interactions) across the diverse farm-household domains helps to foresee trade-offs, synergies and unintended consequences of an intervention. For example, the potential adverse environmental effect from the reduction of organic matter and the trade-off between household nutrition and dispensable budget due to the high market value of the Selected Crops in Doan Ket. This information can contribute to designing and identifying complementary interventions that will improve the positive effect of the NSA intervention. Moreover, the easy and simultaneous calculation of several metrics estimating production diversity, diet diversity, nutrient supply, and nutrition adequacy will facilitate identifying the most robust metrics to infer an intervention's contribution to household dietary requirements across contexts. Among the metrics tested here, the most robust metrics included the count-based nutritional functional diversity (production for consumption and diet) as well as the abundance-based Shannon-Weaver and Simpson's diversity indexes (diet). Similarly, we found the farm system yield to be a novel metric that requires careful interpretation.

The global commitment to ending malnutrition through NSA requires the use of multiple transdisciplinary, holistic and system-oriented approaches. Models such as the farmhousehold model presented here facilitate and foster communication among the multiple disciplines involved in NSA by presenting a set of clearly articulated and tested metrics that can be used to measure both production and nutritional outcomes, two sides of the food system that for so long have been operating in parallel without harnessing their joint potential.

Acknowledgments We thank the CGIAR Research Programs: Humidtropics; Agriculture for Nutrition and Health (A4NH); Roots, Tubers and Bananas (RTB); Water, Land and Ecosystems (WLE) and all the donors who supported this research through their contributions to the CGIAR Fund. For a list of Fund donors, please see http://www.cgiar. org/our-funders/. BesidesWageningen University \& Research also provided strategic funds, under the program 'Global One Health.' We are grateful to the Vietnamese Fruit and Vegetable Research Institute (FAVRI), Dr. Pham Hoi, Son Nuygen, and Lan Huong from CARESVietnam who facilitated, translated and provided logistical help during data collection. We are most grateful to the Vietnamese farmers for their time and patience in supporting this research. We thank Olga Spellman (Bioversity International Science Writing Service) for English and technical editing of this paper.

\section{Compliance with ethical standards}

Conflict of interest The authors confirm that they have no conflict of interest.

Open Access This article is distributed under the terms of the Creative Commons Attribution 4.0 International License (http:// creativecommons.org/licenses/by/4.0/), which permits unrestricted use, distribution, and reproduction in any medium, provided you give appropriate credit to the original author(s) and the source, provide a link to the Creative Commons license, and indicate if changes were made. 


\section{References}

Bellon, M. R., Ntandou-Bouzitou, G. D., \& Caracciolo, F. (2016). Onfarm diversity and market participation are positively associated with dietary diversity of rural mothers in southern Benin, West Africa. PLoS ONE. https://doi.org/10.1371/journal.pone.0162535.

Berti, P. R. (2015). Relationship between production diversity and dietary diversity depends on how number of foods is counted. PNAS, www. pnas.org/cgi/. https://doi.org/10.1073/pnas.1517006112.

Berti, P. R., Krasevec, J., \& Fitzgerald, S. (2004). A review of the effectiveness of agriculture interventions in improving nutrition outcomes. Public Health Nutrition. https://doi.org/10.1079/ PHN2003595.

DeClerck, F. A. J., Fanzo, J., Palm, C., \& Remans, R. (2014). Ecological approaches to human nutrition. Food and Nutrition Bulletin, 32(1), 41-50p.

DeFries, R. S., Fanzo, J., Remans, R., Palm, C., Wood, S., \& Anderman, T. L. (2015). Metrics for land-scarce agriculture. Sciencemag. https://doi.org/10.1126/science.aaa5766.

Devaney, B. L., \& Barr, S. L. (2002). DRI, EAR, RDA, AI, UL: Making sense of this alphabet soup. Nutrition Today, 37(6), 226-232p.

Dinno, A. (2017). Dunn.Test: Dunn's test of multiple comparisons using sums. R package version 1.3.4. https://CRAN.R-project.org/ package $=$ dunn.test

Ditzler, L., Klerkx, L., Chan-Dentoni, J., Posthumus, H., Krupnik, T. J., Ridaura, S. L., Andersson, J. A., Baudron, F., \& Groot, J. C. J. (2018). Affordances of agricultural systems analysis tools: A review and framework to enhance tool design and implementation. Agricultural Systems. https://doi.org/10.1016/j.agsy.2018.03.006.

Ditzler, L., Komarek, A. M., Chiang, T. W., Alvarez, S., Chatterjee, S.A., Timler, C., Raneri, J., Estrada Carmona, N., Kennedy, G., Groot, J.C.J. 2019. A model to examine farm household trade-offs and synergies with an application to smallholders in Vietnam. Agricultural Systems Journal.

Ferdous, Z., Datta, A., Kumar, A., \& Anwar, M. (2016). NJAS Wageningen journal of life sciences development of home garden model for year round production and consumption for improving resource-poor household food security in. NJAS - Wageningen Journal of Life Sciences. https://doi.org/10.1016/j.njas.2016.05.006.

Greiner, T. (2017). Combatting vitamin a deficiency : Overcoming obstacles to optimize the food-based approach. World Nutrition. https:// doi.org/10.26596/wn.201782151-206.

Groot, J. C. J., \& Rossing, W. A. H. (2011). Model-aided learning for adaptive management of natural resources: An evolutionary design perspective. Methods in Ecology and Evolution, 2, 643-650.

Groot, J. C. J., Rossing, W. A. H., Jellema, A., Stobbelaar, D. J., Renting, H., \& Van Ittersum, M. K. (2007). Exploring multi-scale trade-offs between nature conservation, agricultural profits and landscape quality - A methodology to support discussions on land-use perspectives. Agriculture, Ecosystems \& Environment. https://doi.org/ 10.1016/j.agee.2006.03.037.

Groot, J. C. J., Jellema, A., \& Rossing, W. A. H. (2010). Designing a hedgerow network in a multifunctional agricultural landscape: Balancing trade-offs among ecological quality, landscape character and implementation costs. European Journal of Agronomy. https:// doi.org/10.1016/j.eja.2009.07.002.

Groot, J. C. J., Oomen, G. J. M., \& Rossing, W. A. H. (2012). Multiobjective optimization and design of farming systems. Agricultural Systems. https://doi.org/10.1016/j.agsy.2012.03.012.

Groot, J. C. G., Cortez-Arriola, J., Rossing, W. A. H., Améndola-Massiotti, R. D., \& Tittonell, P. (2016). Capturing Agroecosystem vulnerability and resilience. Sustainability. https://doi.org/10.3390/su8111206.
Gustafson, D. I., Gutman, A., \& Leet, W. (2015). Seven food system metrics of sustainable nutrition security. Sustainability. https://doi. org/10.3390/su60x000x.

Herforth, A., \& Ballard, T. J. (2016). Nutrition indicators in agriculture projects: Current measurement, priorities, and gaps. Global Food Security. https://doi.org/10.1016/j.gfs.2016.07.004.

Herforth, A., Nicolo, G. F., Veillerette, B., \& Dufour, C. (2016). Compendium of indicators for nutrition-sensitive agriculture. Roma, Italia. www.fao.org/3/a-i6275e.pdf. Accessed 30 Jan 2018.

Herrero, M., Thornton, P. K., Power, B., Bogard, J. R., Remans, R., Fritz, S., et al. (2017). Farming and the geography of nutrient production for human use: A transdisciplinary analysis. Lancet Planet Health, 1. https://doi.org/10.1016/S2542-5196(17)30007-4.

Hijmans, R. J., Cameron, S. E., Parra, J. L., Jones, G., \& Jarvis, A. (2005). Very high resolution interpolated climate surfaces for global land areas. International Journal of Climatology. https://doi.org/10. 1002/joc. 1276.

Hiwasaki, A., Bolliger, A., Lacombe, G., Raneri, J., Schut, M., \& Staal, S. (2016). Integrated systems research for sustainable smallholder agriculture in the Central Mekong. Achievements and challenges of implementing integrated systems research. Hanoi, Viet Nam: World agroforestry Centre (ICRAF) Southeast Asia regional program. https:// cgspace.cgiar.org/bitstream/handle/10568/78364/isr_mekong_ch5.pdf? sequence $=1$ \&isAllowed=y. Accessed 05 Feb 2018 .

ILRI. (2014). A situational analysis of agricultural production and marketing, and natural resources management systems in Northwest Vietnam. Nairobi, Kenya. https://cgspace.cgiar.org/bitstream/ handle $/ 10568 / 42265 /$ pr vietnamsituationreport.pdf;sequence $=1$. Accessed 06 Feb 2018.

IOM - Institute of Medicine. (2003). Dietary reference intakes. Washington DC: The National Academies Press.

Jones, J. W., Antle, J. M., Basso, B., Boote, K. J., Conant, R. T., Foster, I., et al. (2017). Brief history of agricultural systems modeling. Agricultural Systems. https://doi.org/10.1016/j.agsy.2016.05.014.

Kennedy, G., Ballard, T., \& Dop, M. C. (2011). Guidelines for measuring household and individual dietary diversity. Italy, Rome. http://www. fao.org/fileadmin/user upload/wa workshop/docs/FAOguidelines-dietary-diversity2011.pdf. Accessed 15 Jan 2018.

Khan, N. C., \& Hoan, P. v. (2008). Vietnam recommended dietary allowances 2007. Asia Pacific Journal of Clinical Nutrition, 17(January), 409-415.

Lachat, C., Raneri, J. E., Walker, K., Kolsteren, P., Van Damme, P., Verzelen, K., et al. (2017). Dietary species richness as a measure of food biodiversity and nutritional quality of diets. PNAS. https:// doi.org/10.1073/pnas.1709194115.

Luu, L.T.(2001). The VAC system in northern Viet Nam. In: Integrated agriculture-aquaculture: A primer. FAO/IIRR/WorldFish center. Rome Italy. ISBN 92-5-104599-2. www.fao.org/docrep/005/ Y1187E/Y1187E00.HTM. Accessed 05 April 2018.

Melesse, M. B., Van Den Berg, M., Béné, C., Brouwer, I. D., \& de Brauw, A. 2019. Improving diets through food systems in low- and middleincome countries: Metrics for analysis. IFPRI Discussion Paper 1858. Washington, DC: International Food Policy Research Institute (IFPRI). https://doi.org/10.2499/p15738coll2.133351

Mohri, H., Lahoti, S., Saito, O., \& Mahalingam, A. (2013). Assessment of ecosystem services in homegarden systems in Indonesia, Sri Lanka, and Vietnam. Ecosystem Services. https://doi.org/10.1016/j. ecoser.2013.07.006.

Ngoc Chau, T. T. (2016). Promotion of the consumption of local foods to improve the diet of Vietnamese children. Master's disserationdissertationdissertation. Universiteit Gent, Belgium. 
NIN (2012). Vietnam General Nutrition Survey 2009-2010. General Statistics Office (Viet Nam), Ministry of Health (Vietnam), National Institute of Nutrition (Vietnam), United Nations Children's Fund (UNICEF). https://www.unicef.org/vietnam/ resources_21138.html. Accessed 10 January 2018.

Ogle, B. M., Thi, H., Dao, A., Mulokozi, G., \& Hambraeus, L. (2001). Micronutrient composition and nutritional importance of gathered vegetables in Vietnam. International Journal of Food Science and Nutrition. https://doi.org/10.1080/ 09637480020027000-6-5.

Oksanen, F. G. B., Kindt, R., Legendre, P., Minchin, P. R., O'Hara, R. B., Simpson, G. L., Solymos, P., Stevens H. H., and Wagner, H. (2016). Vegan: Community ecology package. $\mathrm{R}$ package version 2.3-5. https://CRAN.R-project.org/package=vegan

Olson, D. M., Dinerstein, E., Wikramanayake, E. D., Burgess, N. D., Powell, G. V. N., Underwood, E. C., D'Amico, J. A., Itoua, I., Strand, H. E., Morrison, J. C., Loucks, C. J., Allnutt, T. F., Ricketts, T. H., Kura, Y., Lamoreux, J. F., Wettengel, W. W., Hedao, P., \& Kassem, K. R. (2001). Terrestrial Ecoregions of the world: A new map of life on earth. BioScience, 51, 933-938. https:// doi.org/10.1641/0006-3568(2001)051[0933:TEOTWA]2.0.CO;2.

Peet, R. K. (1974). The measurement of species diversity. Annual Review of Ecology and Systematics. https://doi.org/10.1146/annurev.es.05. 110174.001441 .

Petchey, O. L., \& Gaston, K. J. (2007). DendogramsDendrogramsDendrograms and measuring functional diversity. Oikos, http://www. jstor.org/stable/40235189

Powell, B., Thilsted, S. H., Ickowitz, A., Termote, C., Sunderland, T., \& Herforth, A. (2015). Improving diets with wild and cultivated biodiversity from across the landscape. Food Security. https://doi.org/ 10.1007/s12571-015-0466-5.

R Core Team (2016). R: A language and environment for statistical computing. R Foundation for statistical computing, Vienna, Austria. URL https://www.R-project.org/.

Remans, R., Flynn, D. F. B., DeClerck, F., Diru, W., Fanzo, J., Gaynor, K., et al. (2011). Assessing nutritional diversity of cropping systems in African villages. PLoS One. https://doi.org/10.1371/journal.pone. 0021235.

Remans, R., DeClerck, F. A. J., Kennedy, G., \& Fanzo, J. (2015). Expanding the view on the production and dietary diversity link: Scale, function, and change over time. PNAS. https://doi.org/10. 1073/pnas.1518531112.

Ruel, M. T., \& Levin, C. E. (2000). Assessing the potential for food-based strategies to reduce vitamin a and Iron deficiencies: A review of recent evidence (no. 92). Washington D.C. https://page-one.live.cf. public.springer.com/pdf/preview/10.1007/978-1-4020-4948-4_2. Accessed 05 February 2018.

Ruel, M. T., Quisumbing, A. R., \& Balagamwala, M. (2018). Nutrition-sensitive agriculture: What have we learned so far? Global Food Security. https://doi.org/10.1016/j.gfs.2018.01. 002 .

Rufino, M. C., Quiros, C., Boureima, M., Desta, S., Herrero, M., Kiplimo, J., ... Mango, J. (2013). Developing generic tools for characterizing agricultural systems for climate and global change studies (IMPACTlite - phase 2), (January), 1-42. https://cgspace.cgiar.org/ bitstream/handle/10568/42065/Rufino_Report.pdf?sequence= 1\&isAllowed=y. Accessed 10 April 2015 .

Sêdami, A. B., Naéssé, A. V., Pascal, G., \& Firmin, A. D. (2017). Importance of home gardens in rural zone of the municipality of Abomey-Calavi in south of Republic of Benin. Sustainable Agriculture Research. https://doi.org/10.5539/sar.v6n4p150.
Sibhatu, K. T., \& Qaim, M. (2018). Review: Meta-analysis of the association between production diversity, diets, and nutrition in smallholder farm households. Food Policy. https://doi.org/10.1016/j. foodpol.2018.04.013.

Sibhatu, K. T., Krishna, V. V., \& Qaim, M. (2015). Production diversity and dietary diversity in smallholder farm households. PNAS. https:// doi.org/10.1073/pnas.1510982112.

SMILING D3.5-a (2013). Food composition table for Vietnam. National Institute of nutrition, Vietnam. Wageningen University, Netherlands. http://www.fao.org/infoods/infoods/tables-and-databases/asia/en/. Accessed 10 Aug 2017.

Stadlmayr, B., Charrondière, U. R., Enujiugha, V. N., Bayili, R. G., Fagbohoun, E. G., Samb, B., Addy, P., Barikmo, I., Ouattara, F., Oshaug, A., Akinyele, I., Annor, G. A., Bomfeh, K., Ene-Obong, H., Smith, I. F., Thiam, I., \& Burlingame, B. (2012). West African Food Composition Table/ Table De Composition Des Aliments D'afrique De L'ouest. Rome: FAO.

Trinh, L. N., Watson, J. W., Hue, N. N., De, N. N., Minh, N. V., Chu, P., et al. (2003). Agrobiodiversity conservation and development in Vietnamese home gardens. Agriculture Ecosystems \& Environment. https://doi.org/10.1016/S0167-8809(02)00228-1.

Turner, R., Hawkes, C., Waage, J., Ferguson, E., Haseen, F., Hussein, J., et al. (2014). Agriculture for improved nutrition nutrition: The current research landscape. Food and Nutrition Bulletin. https://doi.org/ $10.1177 / 156482651303400401$.

USDA (2007). USDA table of nutrient retention factors release 6. Nutrient data laboratory, Beltsville human nutrition research center (BHNRC), Agricultural Research Service (ARS), U.S. Department of Agriculture (USDA). https://www.ars.usda.gov/ ARSUserFiles/80400525/Data/retn/retn06.pdf. Accessed 10 Aug 2017.

USDA (2016). U.S. Department of Agriculture, Agricultural Research Service. 20xx. USDA National Nutrient Database for standard reference, release. Nutrient data laboratory home page. http://www.ars. usda.gov/nutrientdata. Accessed 10 Aug 2017.

Van Hoi, P.; Nga, T. L.; Raneri, J.; Marie-Soleil, T. (2015). Proposed agricultural and nutrition interventions in Mai son district, son La province. Report for the cooperation project: Improving dietary diversity and diet quality through systems innovation - A pilot study in Vietnam. CARES and Health Bridge. Hanoi, Vietnam.

Van Ittersum, M. K., Rabbinge, R., \& Van Latesteijn, H. C. (1998). Exploratory land use studies and their role in strategic policy making. Agricultural Systems, 58, 309-330.

Verger, E. O., Ballard, T. J., Dop, M. C., \& Martin-Prevel, Y. (2019). Systematic review of use and interpretation of dietary diversity indicators in nutrition-sensitive agriculture literature. Global Food Security, 20, 156-169. https://doi.org/10.1016/j. gfs.2019.02.004.

Vlkova, M., Polesny, Z., \& Verner, V. (2011). Ethnobotanical knowledge and agrobiodiversity in subsistence farming: Case study of home gardens in Phong my commune, Central Vietnam. Genetic Resources and Crop Evolution. https://doi.org/10.1007/s10722-010-9603-3.

Webb, P., \& Kennedy, E. (2014). Impacts of agriculture on nutrition: Nature of the evidence and research gaps. Food and Nutrition Bulletin. https://doi.org/10.1177/156482651403500113.

WorldPop. (2013). Viet Nam 100m Population. Alpha version 2010, 2015 and 2020 estimates of numbers of people per pixel (ppp) and people per hectare (pph), with national totals adjusted to match UN population division estimates (http://esa.un.org/wpp/) and remaining unadjusted. School of Geography and Environmental Science, University of Southampton. https://doi.org/10.5258/ SOTON/WP00297. www.worldpop.org 


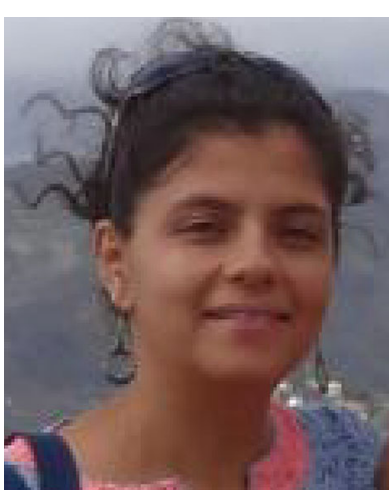

Natalia Estrada-Carmona is a Postdoctoral Fellow at the Farming Systems Ecology Group, Wageningen and Research; and at theProductive and resilient farms, forest and landscapes initiative, Bioversity international. She focuses on estimating, through modeling and participatory approaches, agrobiodiversity's contribution to multifunctional farms and landscapes. Natalia has contributed to projects in Latin America and the Caribbean (Costa Rica, Cuba, and Colombia), Africa (Zambia and Burkina Faso) and Asia (Viet Nam). She has a Ph.D. in natural resources management from the University of Idaho, US and CATIE and holds a MSc on environmental socioeconomics from CATIE, Costa Rica.

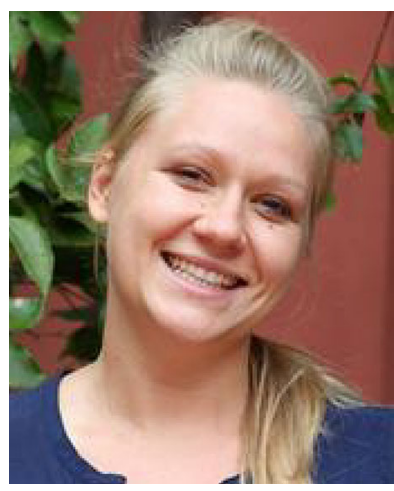

Jessica Raneri is a Research Support Officer at the Nutrition \& Marketing Diversity Programme, Bioversity International. She is involved in designing and implementing 'Agricultural Biodiversity, Nutrition and Dietary' assessments using participatory, qualitative and quantitative methods. She is currently is leading a project in Vietnam designed to improve dietary diversity through an integrated systems perspective. Jessica also supports the Sustainable Diets activities and believes that it is crucial to understand how biodiversity can be utilized to improve the sustainability of food systems and quality of diets.

Jessica started her career as a Clinical Nutritionist in Australia and moved into international research-for-development in 2010. At Bioversity International, she began working on the Conservation \& Availability research area within the scope of ex situ conservation, followed by working with the DDG office developing and validating a 'Rapid Biodiversity Assessment' method in Ghana.

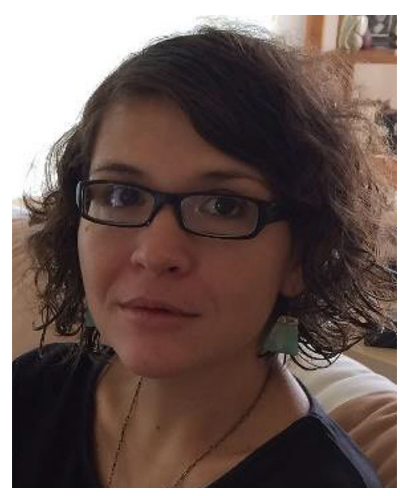

Stephanie Alvarez has a postdoctorate position at Wageningen University, as part of the Farming Systems Ecology team. She is currently involved in the CGIAR research programme "Integrated Systems for the Humid Tropics" and the FAO project "Supporting smallholder farmers in southern Africa to better manage climaterelated risks to crop production and post-harvest handling". She has previously worked for the (French institute) CIRAD on the modelling and analysis of crop-livestock systems in Brazil and Madagascar.

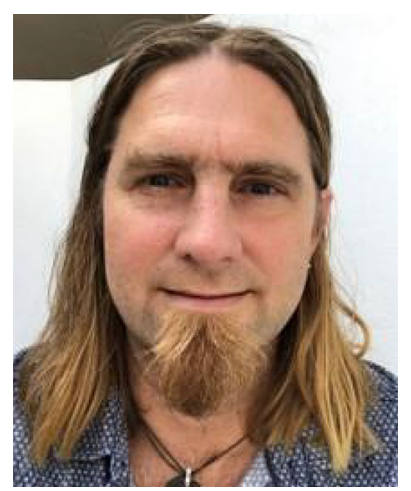

Carl Timler holds a Masters in Organic Agriculture from Wageningen University. $\mathrm{He}$ is currently a Ph.D. candidate in the Farming Systems Ecology Group at Wageningen University. His primary research interests include smallholder farming systems analysis, wholefarm bio-economic modeling, sustainable and ecological intensification, and farm(er) diversity. His experiences lie mostly in Eastern and Southern Africa.

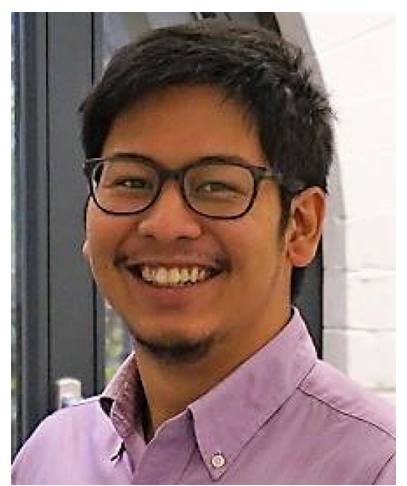

Shantonu Abe Chatterjee is a Ph.D. Candidate and Research Assistant at the Institute of Geography, University of Cologne. His research interests cover agroecological production systems in Japan and India, systems analysis in agriculture, and regional food supply chains, as well as the ethnobotany of "forgotten' vegetables. He has a Master's Degree in Organic Agriculture from Wageningen University.

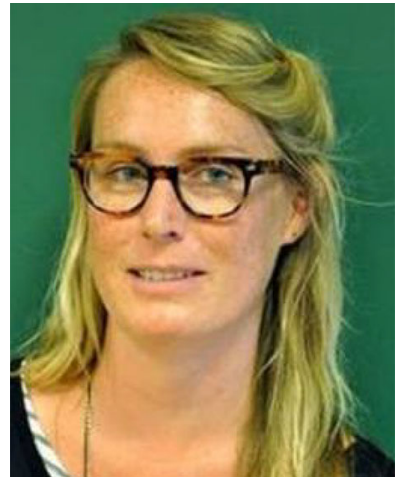

Lenora Ditzler is a Graduate Research Assistant with the Farm Systems Ecology Group at Wageningen University \& Research. She works with a range of farming systems analysis and design tools, including wholefarm models and participatory methods, and has contributed to projects in India, Bangladesh, Vietnam, Ethiopia, and Zimbabwe. In her current research, she is examining the effects of spatial, temporal, and genetic crop diversity on the delivery of agroecosystem services in European arable farming systems. Lenora holds a MSc in Agroecology from the Norwegian University of Life Sciences. 


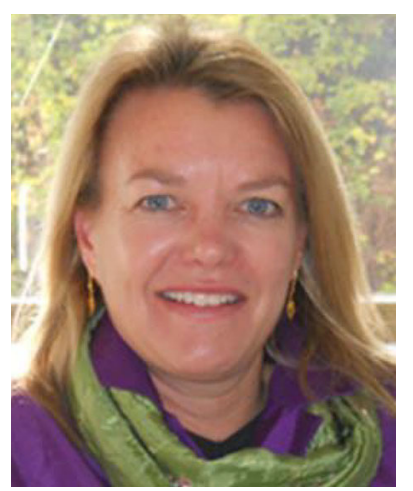

Gina Kennedy is a Scientist with the Nutrition and Marketing Diversity Programme of Bioversity International. For the past ten years, she has worked on nutrition assessment in developing countries, including assessing the contribution of agricultural biodiversity on nutrient intake. Prior to joining Bioversity, she worked for the Nutrition Division of FAO on food-based indicators for use in food and nutrition security programs, nutrition assessment and nutrient requirements. She has a Ph.D. in public health nutrition from Wageningen University and her Master of Public Health from the University of Alabama, Birmingham.

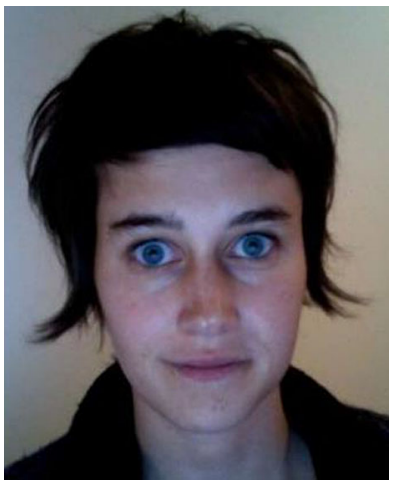

Roseline Remans is an associate research scientist at the Agriculture and Food Security Center, the Earth Institute, Columbia University. Her research focuses on synergies and tradeoffs between agriculture, the environment, and human nutrition. Roseline has a masters and Ph.D. in biosystems engineering from the University of Leuven, in collaboration with CIAT, Colombia, the National Soils Institute, Cuba and El Centro Internacional de Fijacion de Nitrogeno (CIFN), Mexico. She worked for two years at CIFN, Mexico as project coordinator and scientist. After her Ph.D., she joined the Earth Institute supported by a European Marie Curie scholarship.

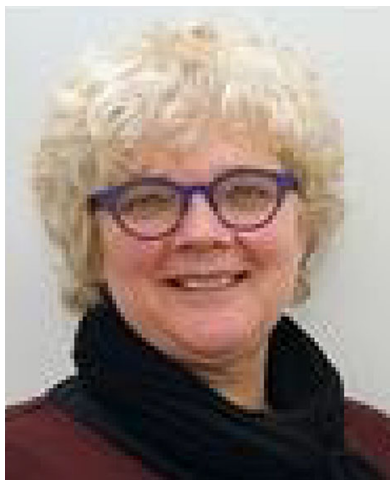

Inge Brouwer is Associate Professor at the Division of Human Nutrition, Wageningen University. Her research focuses on improvement of the dietary quality of (young) women and children, in low and middle-income countries through agricultural or food systems approaches, with special emphasis on micronutrient deficiencies. She has acquired many research funds, from national funding programmes, from EU FP6 and FP7 Framework Programmes as well as from food industries. She coordinated a large

FP7 research programme INSTAPA focusing at the improvement of nutrition through enhancing staple crops (sorghum, millet, maize, and cassava) in Africa through biofortification, fortification and post-harvest processing involving over 40 scientists from European and African countries. She supervised research programmes of more than 20 international Ph.D. fellows in Africa and Asia. At the moment she is the leader of the A4NH Flagship Food Systems for Healthier Diets research programme in collaboration with the CGIAR research institutes.

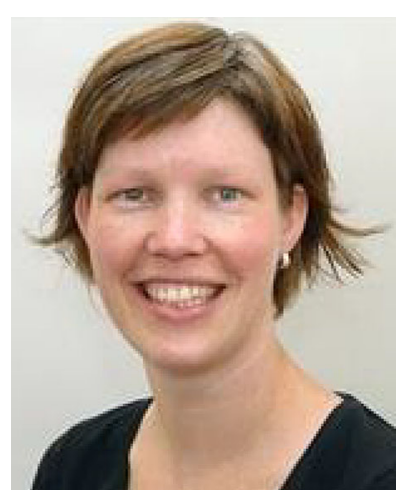

Karin Borgonjen-van den Berg is a Research Dietician at theDivision of Human Nutrition, Wageningen University. Her expertise covers Human Nutrition and Health, Dietary assessment, Food-based dietary guidelines, Dietetics.

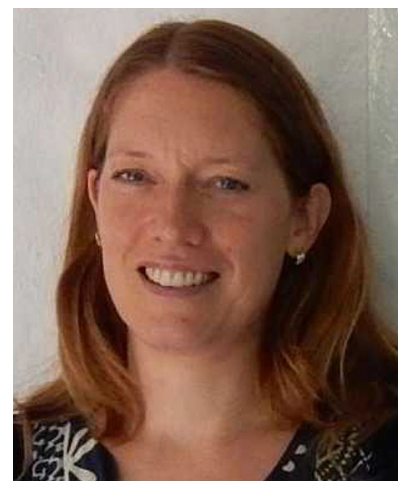

Elise F. Talsma (Ph.D.) is Assistant Professor at the Division of Human Nutrition. Her research focuses on improving food and nutrition security and dietary quality of women, children and adolescents, applying a food system approach in low and middleincome countries.

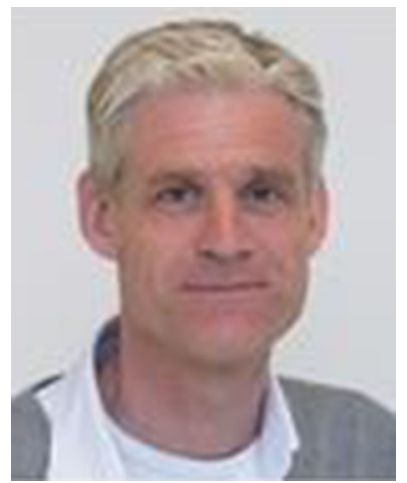

Jeroen C. J. Groot specialized in farming systems analysis, modelbased landscape planning and design, and participatory modeling and gaming. He holds a Ph.D. in Agronomy and MScs in grassland science, animal physiology and tropical animal husbandry. He performed post-doc research in national and international projects concerning nutrient cycling, modeling of sustainability indicators and design of mixed farms in multifunctional landscapes dominated by dairy farming systems. In the EULACIAS project he coordinated model development in a cooperative team effort with universities in Mexico, Uruguay and Argentina. Currently, Dr Groot has a coordinating role in integrated farming systems analysis addressing multi-scale issues of productivity, natural resource management, human nutrition and gender equity for CGIAR Research Programs. Project sites are located in Asia (e.g. Nepal, Bangladesh), Africa (e.g., Ghana, Tanzania, Ethiopia, Malawi) and Latin America (e.g., Ecuador, Uruguay and Mexico). 